Southwest Research Institute

Post Office Drawer 28510, 6220 Culebra Road

San Antonio, Texas 78228-0510

DOE/ER/45063-1/2

\title{
CHARACTERIZATION OF PORE EVOLUTION IN CERAMICS DURING CREEP FAILURE AND DENSIFICATION
}

Final Report

April 15, 1984 - April 14, 1995

R. A. Page and K. S. Chan

Southwest Research Institute

San Antonio, Texas 78284

April 1995

Prepared for the U.S. Department of Energy

Under Grant Number DE-FG05-84ER45063

DISTRIBUTION OF THIS DOCUMENT IS UNLIMTED
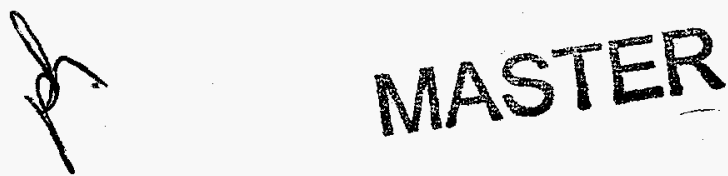

Approved:

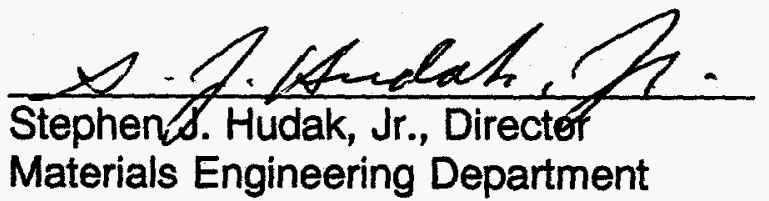




\section{DISCLAIMER}

This report was prepared as an account of work sponsored by an agency of the United States Government. Neither the United States Government nor any agency thereof, nor any of their employees, makes any warranty, express or implied, or assumes any legal liability or responsibility for the accuracy, completeness, or usefulness of any information, apparatus, product, or process disclosed, or represents that its use would not infringe privately owned rights. Reference herein to any specific commercial product, process, or service by trade name, trademark, manufacturer, or otherwise does not necessarily constitute or imply its endorsement, recommendation, or favoring by the United States Government or any agency thereof. The views and opinions of authors expressed herein do not necessarily state or reflect those of the United States Government or any agency thereof. 


\section{DISCLAIMER}

Portions of this document may be illegible electronic image products. Images are produced from the best available original document. 


\section{INTRODUCTION}

This research program was divided into two phases, one involving creep cavitation, the other cavity evolution during sintering. In the former, work was aimed at determining the effect of microstructure and stress state upon creep cavitation, while in the latter, the principal objective was the characterization of pore evolution during sintering.

In order to meet these objectives, the creep cavitation portion of the program was centered around small-angle neutron scattering, supplemented by electron microscopy and precision density measurements. The neutron scattering measurements yielded cavity nucleation and growth rates, and average pore size, distribution, and morphology. These data were used to evaluate current cavitation models, and to implement improved modelling efforts. Additionally, stereoimaging analysis was used to determine grain boundary sliding displacements, which appear to be the critical driving force responsible for cavity nucleation and early growth.

Effort in the pore sintering phase focussed on characterization of pore evolution during intermediate and final stage sintering of alumina using both single and multiple scattering techniques. Electron microscopy, density measurements, and mercury intrusion porosimetry measurements complemented the scattering results. The effects of sintering trajectory, green state, powder morphology, and additives were evaluated. These results were compared to current sintering models.

\section{SUMMARY OF RESULTS}

\section{Creep Cavitation}

Creep damage mechanisms in ceramics both with or without a grain boundary amorphorous phase were studied. For both types of ceramic, creep damage occurs by the nucleation, growth, and coalescence of grain boundary cavities. The regimes of dominance of these individual processes vary with stress, temperature, microstructure, and composition. Cavity 
nucleation in ceramics is a continuous, time-dependent process facilitated by stochastic sliding of grain boundaries and the associated local stress transients at locations such as ledges and triple-grain junctions. Our experimental data indicate that creep cavities in ceramics are nucleated mostly on two-grain junctions by the ledge mechanism, which frequently produces rows of equally spaced and sized cavities along a grain boundary facet. Once nucleated, these cavities may or may not grow, depending on the local tensile stress transient, which is dictated by grain boundary sliding and diffusion. These transient processes lead to three general cavitation behaviors: (1) nucleation-dominated cavitation in which creep damage occurs by continuous nucleation of cavities that would not grow beyond a certain size; (2) growth-dominated cavitation in which transient cavity growth predominates without concurrent cavity nucleation; (3) simultaneous cavity nucleation and growth in a transient manner.

A direct consequence of the relationship between stochastic sliding and cavity nucleation is that the initial growth of sliding-induced cavities is inherently transient; experimental results indicate that significant fractions of a cavity's overall growth occur during this transient. For cavity growth to continue after nucleation, the sliding-induced local tensile stress must not diminish, as a consequence of diffusive or viscous relaxation, at a rate faster than that of the sintering stress. Cavity sintering occurs when the local tensile stress diminishes faster than the sintering stress. For ceramics that show a zero apparent cavity growth rate, the local tensile stress appears to be balanced by the sintering stress. Under this condition, cavitation proceeds by the nucleation of new cavities at regions adjacent to the existing cavities. The joining of these cavities eventually leads to a grain facet cavity. On the other hand, when sufficient tensile stress is maintained, the cavities grow until they coalesce to form a grain facet cavity or crack.

\section{Sintering}

A combination of small-angle neutron scattering (Porod) measurements, multiple smallangle neutron scattering measurements, and mercury intrusion porosimetry measurements was used to investigate the effect of green body density and the role of $\mathrm{MgO}$ sintering aid on the densification of alumina. It was found that the initial connectivity that is established in the green 
body plays a dominant role in establishing the channel diameters during the intermediate stage of sintering. It was demonstrated that this stage is consistent with topological models. It was also shown that the average green density plays a significant role in determining the onset density at which final-stage sintering begins. The role of $\mathrm{MgO}$ as a sintering aid lies, at least in part, in its ability to prolong the stability of the intermediate stage of sintering such that the ceramic body achieves greater density before isolated porosity is formed.

The onset of final-stage sintering was indicated, in both the Porod scattering results and in the MSANS results, by the appearance of an increasing size of the pore radii as densification proceeded. This upturn in pore size, which was not observed to turn down again even when the density reached more than $95 \%$ of theoretical, occurred in the presence of a very significant decrease in the pore number density.

The microstructural parameters of pore radius and grain size were measured at various relative densities for single-phase alumina and alumina containing $12.4 \mathrm{vol} . \%$ zirconia in an attempt to gain a better understanding of the effect of the second phase zirconia addictive on microstructural evolution measurements. Measurements of the pore distributions, obtained from the small-angle neutron scattering have identified a complex pore evolution process. During intermediate stage sintering, the pore channels with the smaller radii were preferentially removed, resulting in a narrowing of the pore distribution and a shift of the distribution peak and the average pore size to larger values. The effect of the zirconia addition during intermediate stage sintering was to increase the rate of removal of the pores at both ends of the distribution. This resulted in narrower pore distributions and larger average pore sizes.

During final stage sintering, the pore distributions began to broaden. The peak of the distributions and the average pore size decreased during the transition from intermediate to final stage sintering and then increased monotonically throughout the remainder of densification. Rapid increases in the moment representative of the higher end of the distributions, $R_{\text {eff }}(0)$, were observed throughout final stage sintering. The zirconia addition resulted in a higher percentage of the larger pores, as evidenced by the higher $R_{\text {eff }}(0)$ values and the comparative volume 
distributions. This observation is thought to be due to the thermodynamic effects of grain growth inhibition by the zirconia.

Grain size/pore size trajectories have illustrated that the zirconia additions resulted in less grain growth but larger pore sizes, as measured by either $\left\langle R>\right.$ or $R_{\text {eff }}(0)$. No sintering models capable of predicting the microstructural trajectories obtained in the study were found. One can, therefore, conclude that development of improved sintering models is necessary if one hopes to be able to predict the pore evolution process in practical powder compacts. 


\section{PUBLICATIONS (DOE SPONSORSHIP)}

1. "Small-Angle Neutron Scattering Study of Creep Cavity Nucleation and Growth in Sintered Alumina," by R. A. Page, J. Lankford, and S. Spooner, Joumal of Materials Science, Vol. 19, p. 3360, 1984.

2. "Nucleation and Early-Stage Growth of Creep Cavities in Hot-Pressed Silicon Carbide," by R. A. Page, J. Lankford, S. Spooner, Acta Metallurgica. Vol. 32, p. 1275, 1984.

3. "Viscous Cavity Growth in Ceramics Under Compressive Loads," by K. S. Chan, J. Lankford, and R. A. Page, Acta Metallurgica. Vol. 32, p. 1907, 1984.

4. "Auger Spectroscopy of Ceramic Grain Boundaries," by R. Sherman, in Microbeam Analysis - 1984 A. D. Romig, Jr., and J. I. Goldstein, eds., San Francisco Press, p. 323, 1984.

5. "Auger Analysis of Hot-Pressed and Sintered Silicon Carbide," by R. Sherman, Journal of the American Ceramic Society Vol. 68, p. C-7, 1985.

6. "Characterization of Creep Cavity Shape in Hot-Pressed Silicon Carbide Using SmallAngle Neutron Scattering," by R. A. Page and S. Spooner, Journal of Materials Science, Vol. 21, p. 1417, 1986.

7. "Creep Cavitation Behavior of Polycrystalline Ceramics," by J. Lankford, K. S. Chan, and R. A. Page, in Fracture Mechanics of Ceramics, Vol. 7 R. C. Bradt, A. G. Evans, D. P. H. Hasselman, and F. F. Lange, eds., Plenum Press, New York, pp. 327-347, 1986.

8. "The Effect of Post-Creep Thermal Treatment on Cavitation Damage," by R. A. Page and J. Lankford, International Journal of High Technology Ceramics. Vol. 2, p. 179, 1986. 
9. "Cavity Nucleation of Grain Boundary Ledges," by K. S. Chan, R. A. Page, and J. Lankford, Acta Metallurgica, Vol. 34, p. 2361, 1986.

10. "Creep Cavitation in Liquid-Phase Sintered Alumina," by R. A. Page, J. Lankford, K. S. Chan, S. Spooner, and K. Hardman-Rhyne, Journal of the American Ceramic Society, Vol. 70, p. 137, 1987.

11. "The Effect of Cyclic Creep on Grain Boundary Cavitation in Ceramics," by R. A. Page and J. Lankford, Journal of Materials Science, Vol. 22, p. 2521, 1987.

12. "Pore Evolution During Glow Discharge Sintering of Alumina," by R. A. Page, S. Spooner, W. B. Sanderson, and D. L. Johnson, Joumal of the American Ceramic Society Vol. 71, p. 1125, 1988.

13. 'The Effect of Ultrasonic Treatments on the Particle Size Distribution and Microstructure of a Slipcast $\mathrm{Al}_{2} \mathrm{O}_{3}$," by C. R. Blanchard and R. A. Page, Ceramic Transactions. Vol. 1. Ceramic Powder Science II. G. L. Messing, E. R. Fuller, Jr., and H. Hauser, eds., The American Ceramic Society, Westerville, OH, pp. 724-732, 1988.

14. "Applications of Small Angle Scattering in Ceramic Research," by R. A. Page, Journal of Applied Crystallography, Vol. 21, p. 795, 1988.

15. "Transient Effects in Creep Cavity Nucleation and Early Growth in Ceramics," by R. A. Page and K. S. Chan, in Advances in Fracture. ICF7, Vol. 4, K. Salama, K. RaviChandar, D. M. R. Taplin and P. Rama Rao, eds., Pergamon Press, New York, pp. 27952803, 1989.

16. "Continuous Creep Cavity Nucleation by Stochastic Grain Boundary Sliding," by K. S. Chan and R. A. Page, Journal of Materials Science, Vol. 25, pg. 4622, 1990. 
17. 'Improved Creep Resistance of a Glass-Bonded Alumina through Concurrent Devitrification," by R. A. Page, and K. S. Chan, Joumal of Materials Science Letters, Vol. 8, p. 938, 1989.

18. "Transient Cavity Growth in Ceramics Under Compression," by K. S. Chan and R. A. Page, Journal of Materials Science, Vol. 27, p. 1651, 1992.

19. "Multiple Small Angle Neutron Scattering Characterization of the Densification of Alumina," by S. Krueger, G. G. Long, and R. A. Page, Materials Research Society Symposium Proceedings, Vol. 166, p. 61, 1990.

20. "Grain Boundary Sliding Measurements in Alumina by Machine Vision Photogrammetry," by C. R. Blanchard and R. A. Page, Journal of Materials Science, Vol. 26, p. 3165, 1991.

21. "Stochastic Aspects of Creep Cavitation in Ceramics," by R. A. Page and K. S. Chan, Metallurgical Transactions, Vol. 18A, p. 1843, 1987.

22. "Transient Effects in Creep Cavity Nucleation and Early Growth in Ceramics," by R. A. Page and K. S. Chan, Advances in Fracture Research. ICF7, K. Salama, K. Ravi-Chandar, D. M. R. Taplin, and P. Rama Rao, eds. Pergamon Press, New York, pp. 2795-803, 1989.

23. "Grain Boundary Sliding Measurements in Alumina by Machine Vision Photogrammetry," by C. R. Blanchard and R. A. Page, Journal of Materials Science, Vol. 26, p. 3165, 1991.

24. "Characterization of the Densification of Alumina by Multiple Small Angle Neutron Scattering," by S. Krueger, G. G. Long, and R. A. Page, Acta Crystallography (Part A). Vol. A47, p. 282, 1991. 
25. "The Effect of Green Density and the Role of MgO Additive on the Densification of Alumina Measured by Small-Angle Neutron Scattering," by G. G. Long, S. Krueger, and R. A. Page, Journal of the American Ceramic Society, Vol. 74, p. 1578, 1991.

26. "Small Angle Neutron Scattering Characterization of Processing/Microstructure Relationships in the Sintering of Crystalline and Glassy Ceramics," by G. G. Long, S. Krueger, R. A. Gerhardt, and R. A. Page, Journal of Materials Research. Vol. 6, p. 2706, 1991.

27. "Evolution of the Pore Size Distribution in Final Stage Sintering of Alumina Measured by Small-Angle X-ray Scattering," by S. Krueger, G. G. Long, D. R. Black, D. Minor, P. R. Jemian, G. W. Nieman, and R. A. Page, Journal of the American Ceramic Society, Vol. 74, p. 2538, 1991.

28. "Grain Boundary Sliding Micro-Displacement Measurements During the Creep of $\mathrm{Al}_{2} \mathrm{O}_{3}$ " by C. R. Blanchard and R. A. Page, Journal of the American Ceramic Society Vol. 75, p. $1612,1992$.

29. "Creep Damage Development in Structural Ceramics," by K. S. Chan and R. A. Page, Journal of the American Ceramic Society, Vol. 76, p. 803, 1993.

30. "Microstructural Evolution During Sintering of Ceramics," by R. A. Page and Y. M. Pan, Synthesis and Processing of Ceramics: Scientific Issues, W. E. Rhine, T. M. Shaw, R. J. Gottschall and Y. Chen, eds., Materials Research Society, Pittsburgh, PA, pp. 449-458, 1992.

31. "The Role of Zirconia Addition in Pore Development and Grain Growth in Alumina Compacts," by Y. M. Pan, R. A. Page, G. G. Long and S. Krueger, Journal of the American Ceramic Society, (submitted). 
32. 'Pore Evolution of Bimodal Powder Compacts," by Y. M. Pan, R. A. Page, G. G. Long, and S. Krueger, Journal of the American Ceramic Society, (submitted).

33. "Microstructural Evolution During Sintering of an Alumina Powder Compact," by R. A. Page, Y. M. Pan, C. R. Blanchard, G. G. Long, S. Krueger, S. Spooner, W. E. Votava, and J. Cesarano III, Journal of the American Ceramic Society (submitted).

34. "The Effect of Fused Alumina Additions on Microstructural Evolution During Sintering," by R. A. Page, Y. M. Pan, G. G. Long, and S. Krueger, Journal of the American Ceramic Society, (submitted).

35. "Microstructural Evolution During Sintering of High Green Density Compacts," by R. A. Page, Y. M. Pan, G. G. Long, and S. Krueger, Journal of the American Ceramic Society (submitted). 


\section{PRESENTATIONS (DOE SPONSORSHIP)}

1. "The Effect of Microstructure on the Nucleation and Early-Stage Growth of Creep Cavities," American Ceramic Society 86th Annual Meeting, Pittsburgh, PA, April 1984.

2. "Viscous Cavity Growth in Ceramics: Theory and Experiment," American Ceramic Society 86th Annual Meeting, Pittsburgh, PA, April 1984.

3. "Cavity Nucleation in Ceramics Under Compressive Loads," American Ceramic Society 87th Annual Meeting, Cincinnati, OH, May 1985.

4. "Nucleation and Early-Stage Growth of Creep Cavities in Alumina," American Ceramic Society 87th Annual Meeting, Cincinnati, OH, May 1985.

5. "The Effect of Post Creep Sintering on Cavitation Damage," American Ceramic Society 87th Annual Meeting, Cincinnati, OH, May 1985.

6. "Creep Cavitation Behavior of Polycrystalline Ceramics," Fourth International Symposium on the Fracture Mechanics of Ceramics, Blacksburg, VA, June 1985.

7. "Creep Failure of Polycrystalline Ceramics," Second International Conference on Fundamentals of Fracture, Gatlinburg, TN, November 1985.

8. "Stochastic Aspects of Creep Cavitation," AIME Annual Meeting, New Orleans, LA, March 1986.

9. "Grain Boundary Cavitation Under Cyclic Creep Conditions," American Ceramic Society 88th Annual Meeting, Chicago, IL, May 1986. 
10. "Pore Evolution During Glow Discharge Sintering of Alumina," American Ceramic Society 89th Annual Meeting, Pittsburgh, PA, April 1987.

11. 'Pore Sintering in Ceramics," Fourth NCSASR Users' Group Meeting, Oak Ridge, TN, May 1987.

12. "The Effect of Ultrasonic Treatments on the Practicle Size Distribution and Microstructure of a Slipcast $\mathrm{Al}_{2} \mathrm{O}_{3}$," First International Conference on Ceramic Powder Processing Science, Orlando, FL, November 1987.

13. "A Stochastic Model for Creep Cavitation in Metals and Ceramics," Fall Meeting of The Metallurgical Society of AIME," Cincinnati, OH, October 1987.

14. "Applications of Small Angle Scattering in Ceramic Research," International Conference on the Applications and Techniques of Small Angle Scattering, Argonne, II, October, 1987.

15. "Small Angle Neutron Scattering in Ceramics Research; Current and Potential Applications," Microstructure and Macromolecular Research with Cold Neutrons, National Bureau of Standards, Gaithersburg, MD, April 1988.

16. "The Relationship Between Grain Boundary Sliding and Creep Cavitation," American Ceramic Society 90th Annual Meeting, Cincinnati, OH, May 1988.

17. "Creep Cavitation in Ceramics: Experiments and Models," 7th International Conference on Fracture, Houston, TX, March 1989.

18. "Small Angle Scattering Measurements of Pore Evolution During Sintering of $\mathrm{Al}_{2} \mathrm{O}_{3}$," American Ceramic Society 91st Annual Meeting, Indianapolis, IN, April 1989. 
19. "Multiple Small Angle Neutron Scattering Characterization of the Densification of Alumina," Materials Research Society Fall Meeting, Boston, MA, November 1989.

20. "Grain Boundary Sliding Measurements of $\mathrm{Al}_{2} \mathrm{O}_{3}$ by Machine Vision Photogrammetry," American Ceramic Society 92nd Annual Meeting, Dallas, TX, April 1990.

21. "Processing-Microstructure Relations During Sintering of Alumina and Porous Silica," American Ceramic Society 92nd Annual Meeting, Dallas, TX, April 1990.

22. "Microstructural Evolution During Sintering," Materials Research Society Fall Meeting, Boston, MA, December 1991.

23. "Small-Angle X-ray Scattering Studies of the Evolution of the Pore Size Distribution in Final Stage Sintering of Alumina," American Ceramic Society 94th Annual Meeting, Minneapolis, MN, April 1992.

24. "Grain Boundary Sliding and Cavitation Measurements During Creep of $\mathrm{Al}_{2} \mathrm{O}_{3}$," American Ceramic Society 94th Annual Meeting, Minneapolis, MN, April 1992.

25. "Grain Boundary Sliding and Cavitation Measurements During Creep of Alumina," American Ceramic Society 95th Annual Meeting, Cincinnati, OH, April, 1993.

26. "Microstructural Evolution in $\mathrm{Al}_{2} \mathrm{O}_{3}$ With and Without $\mathrm{ZrO}_{2}$ Addition by Small-Angle Neutron Scattering Measurements," American Ceramic Society 95th Annual Meeting, Cincinnati, OH, April, 1993.

27. "Creep Damage Development in Structural Ceramics," TMS/ASM Materials Week 93, Rosemont, IL, October 1993.

28. "Microstructure Evolution in Alumina: Effects of Powder Packing and Zirconia Addition," American Ceramic Society 96th Annual Meeting, April 1994. 


\section{APPENDIX}




\title{
The Role of Zirconia Addition in Pore Development and Grain Growth in Alumina Compacts
}

\author{
Yi-Ming Pan and Richard A. Page \\ Southwest Research Institute \\ San Antonio, Texas 78228
}

\author{
Gabrielle G. Long and Susan Krueger \\ National Institute of Standards and Technology \\ Gaithersburg, Maryland 20899
}

\begin{abstract}
The role of $12.4 \mathrm{vol} \% \mathrm{ZrO}_{2}$ addition in the microstructure evolution of alumina compacts during the intermediate and final stages of sintering was investigated by means of small-angle neutron scattering measurements and stereological analysis. Both the pore size evolution results and the grain growth data indicate a narrowly defined onset density for the transition to the final sintering stage. The presence of $\mathrm{ZrO}_{2}$ as a second phase maintains the stability of the intermediate sintering stage out to significantly higher density and plays an important role in inhibiting grain growth and in preventing pore-grain boundary separation. The influence of the $\mathrm{ZrO}_{2}$ second phase on pore evolution, grain growth, and sinterability of the alumina-zirconia composite is discussed with reference to the behavior of single-phase alumina.
\end{abstract}




\section{INTRODUCTION}

The effects of $\mathrm{ZrO}_{2}$ inclusions on the grain growth and sinterability of $\mathrm{Al}_{2} \mathrm{O}_{3}$ have been investigated by Lange et al. ${ }^{1.2}$. They found that $\mathrm{Al}_{2} \mathrm{O}_{3}$ compacts containing enough $\mathrm{ZrO}_{2}(>5$ vol.\%) to fill most of the four-grain junctions in the alumina matrix showed more effective grain growth control than those with low $\mathrm{ZrO}_{2}$ compositions ( $<2.5$ vol.\%) in which only some of the four-grain junctions were filled. ${ }^{1}$ Since the $\mathrm{ZrO}_{2}$ inclusions move with the alumina four-grain junctions, the grain growth hindrance was attributed to the dragging force exerted on the $\mathrm{Al}_{2} \mathrm{O}_{3}$ grains by the $\mathrm{ZrO}_{2}$ inclusions. These results are consistent with a pore-drag model developed by Evans and co-workers. ${ }^{3,4}$ Lange et al. ${ }^{2}$ also showed that the $\mathrm{ZrO}_{2}$ inclusion phase delayed the initiation of bulk shrinkage. They also discussed sintering behavior from a thermodynamic viewpoint of pore closure, indicating that since pores coordinated by more than a critical number of grains are thermodynamically stable, some grain growth may be beneficial in densification.

Another perspective on sinterability of $\mathrm{Al}_{2} \mathrm{O}_{3} / \mathrm{ZrO}_{2}$ composites was developed by $\mathrm{Zhao}$ and Harmer ${ }^{5}$ in a study of the effect of pore distribution on microstructure development taking into account both the thermodynamics and the kinetics of pore shrinkage. Their experimental results on the sintering of undoped, $\mathrm{MgO}$-doped, and 10 vol.\% $\mathrm{ZrO}_{2}$-doped alumina impregnated with large pores showed that, although the grain-growth rate was significantly suppressed by the $\mathrm{ZrO}_{2}$ addition, a slightly higher product density was achieved. Zhao and Harmer attributed this beneficial sintering effect to the smaller grain size and associated faster kinetics. They also concluded that the accelerated kinetics associated with inhibited grain growth were more important than the favorable thermodynamics obtained by grain growth.

The effect of grain growth on pore stability, originally studied by Kingery and Francois, ${ }^{6}$ has been extensively discussed by a number of investigators. ${ }^{7,8}$ As pointed out by Kingery and Francois and others, pore stability depends on both the dihedral angle and the pore/grain size ratio; and there is a critical pore coordination number above which the pore is stable, and below which it is unstable. Consequently, if grain growth reduces the number of grains coordinating a stable pore to the critical 
number, the pore would either shrink and disappear or become isolated from grain boundaries, whereas if the pore coordination number remains larger than the critical value, the pore would remain stable. There is a chance that such stable pores will grow at the expense of smaller ones as the pores migrate along the grain boundaries, coarsening into larger pores as grain growth proceeds.

Neither Zhao and Harmer ${ }^{5}$ nor Lange et al. ${ }^{1,2}$ characterized the evolution of the pore size distribution during densification in their studies. The effect of the $\mathrm{ZrO}_{2}$ second-phase addition on pore evolution is, thus, uncertain. This study represents an attempt to better understand the kinetic and thermodynamic effects of $\mathrm{ZrO}_{2}$ additions on microstructural evolution, particularly pore evolution. In earlier studies ${ }^{9-11}$, the pore-size evolution of alumina, with and without magnesia sintering aid, was measured using multiple small-angle neutron scattering (MSANS) and small-angle X-ray scattering (SAXS) techniques. Those studies found that the role of $\mathrm{MgO}$ as a sintering aid lies, at least in part, in prolonging the stability of intermediate-stage sintering such that the body achieves greater density before the transition to isolated porosity takes place, leading to a finer-grained finished ceramic. In the present investigation, microstructure evolution in $\mathrm{Al}_{2} \mathrm{O}_{3} / \mathrm{ZrO}_{2}$ powder compacts was measured both by MSANS and by stereological analysis. $\mathrm{A}$ comparison of these results with previous results for single-phase $\mathrm{Al}_{2} \mathrm{O}_{3}$ compacts is used to identify the effect of zirconia on pore coarsening, grain growth, and sinterability of alumina compacts.

\section{EXPERIMENTAL PROCEDURE}

\section{(1) Samples}

$\mathrm{Al}_{2} \mathrm{O}_{3}$ samples containing 12.4 vol.\% $\mathrm{ZrO}_{2}$ were prepared from Baikowski alumina (CR6, $6 \mathrm{~m}^{2} / \mathrm{g}$ ) and Toyo Soda zirconia stabilized with $3 \mathrm{~mol} . \%$ yttria (TZ-3Y, $16 \mathrm{~m}^{2} / \mathrm{g}$ ). The ceramic powders were ultrasonically dispersed in distilled water, along with $0.5 \mathrm{wt} . \%$ of a polyelectrolyte dispersant*, to reach a solid content of $45 \mathrm{vol} . \%$, and slip cast to green densities of approximately

* Darvan C., R.T. Vanderbilt Co., Norwalk, CT. 
$54 \%$ of theoretical density (TD), where $\mathrm{TD}=4.24 \mathrm{~g} / \mathrm{cm}^{3}$. The green compacts were formed in PTFE molds placed on top of plaster-of-paris blocks. After 55 minutes, the molds were removed from the blocks and sealed in a container overnight. The partially dried samples were then removed from the molds and resealed into a container for 2 days, after which the container was opened to the air for from 5 to 7 days. Finally, the following series of oven-drying steps was conducted: 2 days at $64^{\circ} \mathrm{C}, 1$ day at $81^{\circ} \mathrm{C}, 1$ day at $102^{\circ} \mathrm{C}$, and 1 day at $116^{\circ} \mathrm{C}$. This procedure prevented cracking and thus produced a dry solid green body. The samples were then sintered at $1600^{\circ} \mathrm{C}$ in air for different soaking periods using identical heating curves (see Ref. 9, Fig. 2).

\section{(2) Conventional Characterizations}

Green density was measured by the geometric method, and the sintered density was measured by Archimedes' method with water as the immersion medium. Thermal etching of polished samples was performed at $1500^{\circ} \mathrm{C}$ for 1 hour to reveal grain boundaries and other microstructural features. Both polished, thermally etched surfaces and fracture surfaces were examined by scanning electron microscopy (SEM). Stereological analyses were performed on transparencies on which grain boundaries were traced directly from SEM micrographs. An areal analysis method was used to determine the mean size and the size distribution of both $\mathrm{Al}_{2} \mathrm{O}_{3}$ and $\mathrm{ZrO}_{2}$ grains.

\section{(3) Small-Angle Scattering Measurements}

Detailed descriptions of the experimental techniques employed to characterize porosity using MSANS and SAXS have been presented in a number of earlier studies. ${ }^{9-11}$ The formalisms employed in the analysis of the small-angle scattering data have also been thoroughly discussed., ${ }^{9,12}$ Hence, only a brief description of the scattering techniques and formalisms will be presented here.

The interaction that occurs between a neutron and a pore during a scattering event produces a phase shift, $v$, in the neutron. The phase shift depends on the scattering contrast of the pore relative to the matrix, $\Delta \rho$, the neutron wavelength, $\lambda$, and the pore size, $2 R$, and is given by 


$$
v=2 \Delta \rho \lambda R
$$

For porous ceramic compacts, generally $0.1 \leq v \leq 2$ at small scattering wavevectors, $Q$ (where $Q=$ $(4 \pi \lambda) \sin \theta$ and $2 \theta$ is the angle of scatter), and the scattering is dominated by incoherent-multiple-neutron scattering. At large $Q$, single scattering dominates. ${ }^{12}$ Hence, MSANS techniques were used to characterize the small $Q$ regime and classical single scattering techniques were used in the large $Q$ regime.

The neutron scattering measurements were performed on a 30 m instrument at the $20 \mathrm{MW}$ research reactor at the National Institute of Standards and Technology. The MSANS data, obtained for each sample at four different incident wavelengths ranging from 0.6 to $2.0 \mathrm{~nm}$ and sample-to-detector distances of 3.6, 8.0, and $15.3 \mathrm{~m}$ and no beam stop in place, were circularly averaged to produce one-dimensional intensity, $I(Q)$, versus scattering wavevector, $Q$, curves. Gaussian fits were made to each curve in the $Q$ range beginning at an intensity of $\approx 85-90 \%$ of $I(0)$ and extending to $\approx 45 \%$ of $I(0)$. For each curve fit, a radius of curvature, $r_{c}$, was extracted from the standard deviation, $\sigma$, such that

$$
r_{c}=(1 / 2 \sigma)^{1 / 2}
$$

Blank spectra, measured at each wavelength with no scatterer in place, were also fitted and a correction for the instrument function was made. The radius, $R$, of the pores, was extracted from each corrected scattering curve using the following empirical formula developed for the description of multiple scattering: ${ }^{12}$

$$
r_{c}[Q R]=0.926\left\{\bar{z} \ln ^{0.85} \bar{z}\right\}^{0.5} \quad(\text { for } \bar{z} \geq 5)
$$

where $\bar{z}$, the scattering power, is given by

$$
\bar{z}=1.5 \phi z(\Delta \rho \lambda)^{2} R
$$


with $\varphi$ being the pore volume fraction and $\mathrm{z}$ the sample thickness. The values of $\mathrm{R}$ derived from the scattering curve from each of the four wavelengths were averaged to obtain an effective radius, $R_{\text {eff }}(0)$, for the scattering pores in each sample. Each value of $R_{\text {eff }}(0)$ was refined by allowing both $R$ and $\varphi$ to vary and using a least-squares fitting method and the full MSANS formalism. ${ }^{12}$

The large $Q$ portions of the scattering curves, which are dominated by classical single-scattering, were obtained at an incident neutron wavelength of $0.6 \mathrm{~nm}$ and a sample-to-detector distance of $3.5 \mathrm{~m}$. The data were corrected for parasitic scattering and beam-blocked background, and were placed on an absolute scale using a secondary standard. They were then radially averaged to obtain the differential scattering cross-section, $d \Sigma / d \Omega$, which exhibited classical Porod ${ }^{13}$ behavior. The scattering in the Porod region was used to obtain the total pore surface area normalized to unit volume, $S / V$, from

$$
Q^{4} \frac{d \Sigma}{d \Omega}=2 \pi(\Delta \rho)^{2}(S / V)
$$

and the Porod radius, $R_{\text {eff }}(\infty)$, from

$$
R_{e f f}(\infty)=3 \phi(V / S)
$$

\section{RESULTS}

\section{(1) Sintering Behavior and Microstructure Development}

The sintered density versus time results, shown in Figure 1, can be used to compare the sinterability of the $\mathrm{Al}_{2} \mathrm{O}_{3} / \mathrm{ZrO}_{2}$ composite containing 12.4 vol.\% $\mathrm{ZrO}_{2}$ with the undoped single-phase $\mathrm{Al}_{2} \mathrm{O}_{3}$ samples (our "13-series") characterized in earlier studies. 9.10 Whereas, the presence of the $\mathrm{ZrO}_{2}$ phase slightly retarded densification of the samples during the intermediate sintering stage, the $\mathrm{Al}_{2} \mathrm{O}_{3} / \mathrm{ZrO}_{2}$ samples ultimately reached sintered densities only slightly lower than the 
single-phase $\mathrm{Al}_{2} \mathrm{O}_{3}$ samples after sintering at $1600^{\circ} \mathrm{C}$ for $30 \mathrm{~min}$. or longer. For example, final densities of $98.4 \% \mathrm{TD}$ for the $\mathrm{Al}_{2} \mathrm{O}_{3} / \mathrm{ZrO}_{2}$ sample and $98.9 \%$ TD for the pure $\mathrm{Al}_{2} \mathrm{O}_{3}$ sample were obtained after sintering at $1600^{\circ} \mathrm{C}$ for $300 \mathrm{~min}$.

Figure 2 shows the microstructure development of the $\mathrm{Al}_{2} \mathrm{O}_{3} / \mathrm{ZrO}_{2}$ samples at various densities provided by sintering at $1600^{\circ} \mathrm{C}$ with different periods of soaking. As shown in the figure, the microstructures of the $\mathrm{Al}_{2} \mathrm{O}_{3} / \mathrm{ZrO}_{2}$ samples were uniformly developed and the grain size grew gradually as densification proceeded. The majority of the $\mathrm{ZrO}_{2}$ grains, identified by the contrast change in the backscattering images, were located at the grain junctions of the matrix. Although significant grain growth, particularly in the alumina matrix, can be seen in sample 12-5 with a relative density of $98.4 \% \mathrm{TD}$, abnormal grain growth did not develop and no pore-grain boundary separation was observed in the $\mathrm{Al}_{2} \mathrm{O}_{3} / \mathrm{ZrO}_{2}$ samples throughout sintering.

Figure 3 shows $\mathrm{SEM}$ micrographs of the single-phase $\mathrm{Al}_{2} \mathrm{O}_{3}$ samples at different densities. Abnormal grain growth started to develop in the single-phase $\mathrm{Al}_{2} \mathrm{O}_{3}$ samples when the density reached $85.4 \% \mathrm{TD}$ (sample 13-5). A number of small pores became separated from grain boundaries and entrapped inside the $\mathrm{Al}_{2} \mathrm{O}_{3}$ grains in this sample which was sintered to $1600^{\circ} \mathrm{C}$ without soaking, indicating the onset density of the pore morphology transition from cylindrical to isolated pores had been reached. This provides proof of the hypothesis in reference 9 that the transition to final-stage sintering commences at this density. The development of faceted abnormal grains appeared in sample $13-8$ after sintering for a longer period $\left(300 \mathrm{~min}\right.$ at $\left.1600^{\circ} \mathrm{C}\right)$. Differences in the locations of the pores were also observed. In the $\mathrm{Al}_{2} \mathrm{O}_{3} / \mathrm{ZrO}_{2}$ samples, all the pores were located on grain boundaries. In contrast, pores trapped inside the large grains were seen in the single-phase alumina samples. The separation of pores from grain boundaries observed in the pure alumina compacts is directevidence for the onset of abnormal grain growth, a process that limits densification of the powder compacts. 


\section{(2) Pore Coarsening and Grain Growth}

Table 1 lists the experimental MSANS parameters and the effective pore radii, $R_{\text {eff }}(0)$, for the slip-cast alumina-zirconia samples. It should be mentioned that to apply the MSANS formalism, the constraints of $\bar{z} \geq 10$ and a phase shift, $v$, ranging from 0.1 to 2 must be satisfied. However, Berk and Hardman-Rhyne ${ }^{12}$ showed that if $\bar{z}$ is sufficiently large, the MSANS formalism may even apply if $v>2$. The $\mathrm{R}_{\text {eff }}(0)$ values for the $\mathrm{Al}_{2} \mathrm{O}_{3} / \mathrm{ZrO}_{2}$ samples, calculated from the MSANS measurements, are plotted versus sintered density in Figure 4. Previous neutron scattering results for the single-phase $\mathrm{Al}_{2} \mathrm{O}_{3}$ samples ${ }^{9,10}$ are also included in this figure for comparison. As seen in Figure 4, the $\mathrm{R}_{\text {efr }}(0)$ versus density trajectories were quite similar for the $\mathrm{Al}_{2} \mathrm{O}_{3} / \mathrm{ZrO}_{2}$ and the $\mathrm{Al}_{2} \mathrm{O}_{3}$ samples. $R_{\text {eff }}(0)$ remained close to its original green state value during intermediate stage sintering. However, $\mathrm{R}_{\text {eff }}(0)$ increased sharply during final stage sintering of $\mathrm{Al}_{2} \mathrm{O}_{3} / \mathrm{ZrO}_{2}$. This trend is also observed in undoped alumina and alumina with $0.25 \mathrm{wt} \% \mathrm{MgO}$ additive prepared by either slip-casting or cold-pressing from the same alumina powders. ${ }^{9.10}$ However, the rate at which $R_{\text {efr }}(0)$ increased during final stage sintering increased as a result of the $\mathrm{ZrO}_{2}$ addition. This is more clearly seen in the $R_{\text {eff }}(0)$ versus sintering time curves presented in Figure 5. The delayed transition into final stage sintering exhibited by the $\mathrm{Al}_{2} \mathrm{O}_{3} / \mathrm{ZrO}_{2}$ samples is also reflected by the smaller $\mathrm{R}_{\text {err }}(0)$ values exhibited by the $\mathrm{Al}_{2} \mathrm{O}_{3} / \mathrm{ZrO}_{2}$ samples at hold times of 30 minutes or less.

The $R_{\text {eff }}(0)$ values discussed above represent only one moment $\left(\left\langle R^{4}\right\rangle \mid\left\langle R^{3}\right\rangle\right.$, where \langle\rangle denotes an average over the ensemble) of the pore size distribution. $R_{\text {eff }}(0)$ is thus weighted toward the high end of the distribution. A second moment of the pore size distribution $\left(\left\langle R^{3}\right\rangle \mid\left\langle R^{2}\right\rangle\right)$ was obtained from the single scattering present in the Porod region. This moment, $R_{\text {eff }}(\infty)$, is weighted to smaller pore sizes than is $\mathrm{R}_{\text {eff }}(0)$. However, it still represents a moment that is significantly above the mean of the distribution. The $\mathrm{R}_{\text {eff }}(\infty)$ values obtained from the Porod region for the $\mathrm{Al}_{2} \mathrm{O}_{3} / \mathrm{ZrO}_{2}$ samples are presented in Table 2 . 
Additional information about pore evolution can be obtained by examining how the pore size distributions may be changing during densification. Previous small-angle $x$-ray scattering measurements of a number of the high density (97-99\% TD), single-phase $\mathrm{Al}_{2} \mathrm{O}_{3}$ samples ${ }^{11}$ suggest that the pore size distribution present during final stage sintering can be approximated by a log-normal distribution. Although similar small-angle X-ray scattering derived pore size distributions are not available for intermediate-stage sintering samples, we will assume log-normal behavior exists throughout densification. Number weighted pore size distributions were, thus, determined for each of the $\mathrm{Al}_{2} \mathrm{O}_{3} / \mathrm{ZrO}_{2}$ and $\mathrm{Al}_{2} \mathrm{O}_{3}$ samples using the assumed log-normal behavior and the two moments of the distribution described by $R_{\text {eff }}(0)$ and $R_{e f f}(\infty)$. In this manner, complete pore size distributions were determined. A thorough discussion of the methods involved in determining the size distributions can be found in reference 14 . The mean of the distribution, $\langle R>$, the peak of the distribution, $\mathbf{R}_{\text {mode }}$, and the width parameter of the distribution, $\beta$, were determined from

$$
\begin{gathered}
<R>=R_{e f f}^{3}(\infty) / R_{e f f}^{2}(0) \\
R_{\text {mode }}=\frac{<R>}{\exp \left(1.5 \beta^{2}\right)}
\end{gathered}
$$

and

$$
\beta=\sqrt{\ln }\left[R_{e f f}(0) / R_{e f f}(\infty)\right]
$$

respectively. These values are listed in Table 3.

The parameters defined by Equations (7), (8), and (9) and listed in Table 3 are representative of the number weighted pore distributions. To provide a better illustration of the important larger pores in the distribution, the number weighted distributions were converted to volume weighted distributions. Volume weighted size distributions illustrating the evolution of the pore distributions going from the green state to near full density are presented for the $\mathrm{Al}_{2} \mathrm{O}_{3} / \mathrm{ZrO}_{2}$ and single-phase 
$\mathrm{Al}_{2} \mathrm{O}_{3}$ materials in Figures 6 and 7, respectively. These figures, in which the volume is plotted on a logarithmic axis to facilitate comparison of samples with large differences in total pore volume, indicate that the two ends of the distribution decreased more rapidly than the center during sintering from the green state up to $91 \%$ TD. However, further sintering to near full density resulted in a decrease in the volume of small pores and an increase in the volume of large pores. The increase in the volume of large pores implies that substantial pore coarsening occurs during final stage sintering.

Figures 8-10, which provide comparisons of the volume weighted pore size distributions for $\mathrm{Al}_{2} \mathrm{O}_{3} / \mathrm{ZrO}_{2}$ and single-phase $\mathrm{Al}_{2} \mathrm{O}_{3}$ samples sintered to similar densities, illustrate the effect of the $\mathrm{ZrO}_{2}$ addition on the evolution of the pore size distribution. In the green state, the single-phase $\mathrm{Al}_{2} \mathrm{O}_{3}$ sample contained a higher volume of pores with radii greater than approximately $0.15 \mu \mathrm{m}$. By about $91 \% \mathrm{TD}$, the $\mathrm{Al}_{2} \mathrm{O}_{3} / \mathrm{ZrO}_{2}$ sample had developed a higher volume of pores with radii between $0.15 \mu \mathrm{m}$ and $0.4 \mu \mathrm{m}$, but the single-phase $\mathrm{Al}_{2} \mathrm{O}_{3}$ sample maintained a higher volume of pores with radii greater than $0.4 \mu \mathrm{m}$. By between 98 and $99 \% \mathrm{TD}$, however, the $\mathrm{Al}_{2} \mathrm{O}_{3} / \mathrm{ZrO}_{2}$ sample exhibited a higher volume of pores with radii greater than about $0.5 \mu \mathrm{m}$. Thus, when sintered to near full density, the $\mathrm{Al}_{2} \mathrm{O}_{3} / \mathrm{ZrO}_{2}$ material contained a higher volume of large pores compared to the single-phase $\mathrm{Al}_{2} \mathrm{O}_{3}$ even though it started in the green state with a smaller volume of large pores.

A number of similarities between the $\mathrm{Al}_{2} \mathrm{O}_{3} / \mathrm{ZrO}_{2}$ and $\mathrm{Al}_{2} \mathrm{O}_{3}$ materials are evident from the data. Both materials exhibited steadily increasing $<R>$ and $R_{\text {mode }}$ values, as shown in Figures 11 and 12 , and a narrowing of the number weighted pore size distribution, as indicated by the decreasing $\beta$ values in Table 3, throughout the intermediate sintering stage. Both materials also exhibited substantial drops in $<R>$ and $R_{\text {mode }}$ between $91 \%$ TD and $95 \%$ TD followed by rapid increases during the remainder of the final sintering stage. The decreases in $<R>$ and $R_{\text {mode }}$ are brought about by the transition from a narrowing pore distribution, decreasing $\beta$, to a broadening distribution, increasing $\beta$, that also occurred at between $91 \%$ TD and 95\% TD in both systems. Based on the density at which they occur, it appears that the transition from a narrowing to a broadening 
distribution and the corresponding drops in $\left\langle R>\right.$ and $R_{\operatorname{mode}}$ are related to the transition from the open pores that are characteristic of intermediate stage sintering to the closed pores that are characteristic of final stage sintering. Although the trends exhibited by $\left\langle R>, R_{\text {mode }}\right.$, and $\beta$ were similar in both systems, the extent of the changes was material dependent. The $\mathrm{Al}_{2} \mathrm{O}_{3} / \mathrm{ZrO}_{2}$ samples exhibited larger values of $\left\langle R>\right.$ and $R_{\text {mode }}$ throughout densification and smaller values of $\beta$ during intermediate stage sintering. Hence, the $\mathrm{ZrO}_{2}$ addition resulted in a larger mean pore size at all stages of densification and a narrower pore size distribution during intermediate stage sintering.

The results presented above were obtained from the SANS measured parameters of $R_{\text {eff }}(0)$ and $\mathrm{R}_{\mathrm{eff}}(\infty)$ and an assumption that the pore size distributions were log-normal. The size distributions of Figures 6-10 and the values of $\langle R\rangle, R_{\text {mode }}$ and $\beta$ in Table 3 are dependent on the validity of the $\log$-normal shape assumption. The trends exhibited by $\langle R\rangle, R_{\text {mode }}$, and $B$, on the other hand, are a reflection of the behavior of the moments $\left\langle R^{4}\right\rangle \mid\left\langle R^{3}\right\rangle$ and, $\left\langle R^{3}\right\rangle \mid\left\langle R^{2}\right\rangle$ which are determined from $R_{\text {eff }}(0)$ and $R_{\text {eff }}(\infty)$ and, as such, are not dependent on the validity of the assumed distribution shape. Thus, the findings regarding a narrowing distribution with gradually increasing mean pore size during intermediate stage sintering and a broadening distribution with a more rapidly increasing mean pore size during final stage sintering should be valid irrespective of the actual shape of the pore size distribution, provided that the distribution is unimodal.

Figure 13 shows the mean grain size versus time behavior of the single-phase and $\mathrm{ZrO}_{2}$-containing alumina samples sintered at $1600^{\circ} \mathrm{C}$. The $\mathrm{ZrO}_{2}$ second phase was very effective in inhibiting grain growth of the $\mathrm{Al}_{2} \mathrm{O}_{3}$ grains, at least within the range of sintering conditions investigated in the present study. Without the $\mathrm{ZrO}_{2}$ present, the mean alumina grain size increased from $0.52 \mu \mathrm{m}$ with no soaking time at $1600^{\circ} \mathrm{C}$ to $1.80 \mu \mathrm{m}$ after $300 \mathrm{~min}$. at $1600^{\circ} \mathrm{C}$. With the 12.4 vol. $\% \mathrm{ZrO}_{2}$, the mean alumina grain size increased from $0.46 \mu \mathrm{m}$ with no soaking time at $1600^{\circ} \mathrm{C}$ to $1.05 \mu \mathrm{m}$ after $300 \mathrm{~min}$. at $1600^{\circ} \mathrm{C}$. The mean size of the $\mathrm{ZrO}_{2}$ grains remained constant out to a 300 min. hold at $1600^{\circ} \mathrm{C}$. As shown in Figure 14, the mean size of the $\mathrm{Al}_{2} \mathrm{O}_{3}$ grains increased 
monotonically with increasing density during intermediate stage sintering, unlike the porous phase. However, in the final sintering stage, grain growth accelerated dramatically, just as the pore size shown in Figure 4.

Table 4 lists the statistical data for the mean grain size of both $\mathrm{Al}_{2} \mathrm{O}_{3}$ and $\mathrm{ZrO}_{2}$ phases, obtained from the stereological measurements using the areal analysis method. This table also includes the values of the standard deviation of the mean grain size which was seen to increase as sample density increased, particularly in the single-phase $\mathrm{Al}_{2} \mathrm{O}_{3}$ samples. The large values of the standard deviation for the single-phase samples at the highest densities were a direct result of abnormal grain growth, which is consistent with the microstructural observations. The measured grain size distributions of samples $12-5$ and $13-8$ sintered under identical conditions $\left(1600^{\circ} \mathrm{C} / 300 \mathrm{~min}\right.$.) are compared in Figure 15. It is clear that the $\mathrm{Al}_{2} \mathrm{O}_{3} / \mathrm{ZrO}_{2}$ sample had a narrower distribution and a smaller mean grain size than the single-phase $\mathrm{Al}_{2} \mathrm{O}_{3}$ sample which had a very broad grain size distribution containing a number of large faceted grains.

\section{DISCUSSION}

This study follows the evolution of both the pore-size and the grain-size distributions in a single-phase alumina and an alumina with 12.4 vol.\% of zirconia to gain a better understanding of the role that the zirconia second-phase addition plays during sintering. The results of this study have revealed a complex pore evolution process in both the $\mathrm{Al}_{2} \mathrm{O}_{3} / \mathrm{ZrO}_{2}$ and the single-phase $\mathrm{Al}_{2} \mathrm{O}_{3}$ materials. During intermediate stage sintering, $R_{\text {eff }}(0)$ changed slightly while $<R>$ and $R_{\text {mode }}$ increased continuously, the pore distribution narrowed, and grain size increased gradually. During final stage sintering, the pore distribution broadened and $R_{\text {eff }}(0),\left\langle R>, R_{\text {mode }}\right.$ and the grain size all exhibited accelerated rates of increase. Additionally, drops in $<R>$ and $R_{\text {mode }}$ were observed between about $91 \%$ and $95 \%$ TD. These drops were related to the transition from a narrowing distribution to a broadening distribution that appears to occur during the transition from intermediate to final stage sintering. Although similar trends were observed in both materials, the magnitudes of the 
microstructural changes were significantly altered by the $\mathrm{ZrO}_{2}$ additions. Increases in $\mathrm{R}_{\text {efr }}(0),<\mathrm{R}>$ and $R_{\text {mode }}$ were much larger, narrowing of the pore distribution during intermediate stage sintering was more extensive, and increases in mean grain size were smaller with the $\mathrm{ZrO}_{2}$ addition.

Each of the microstructural parameters discussed above exhibited distinct intermediate stage and final stage behaviors. For the $\mathrm{ZrO}_{2}$ containing material, the transitions in each of these microstructural parameters occurred between 92 and $96 \%$ TD. Since this was also the density at which isolated pores began to appear, we conclude that this transition point corresponds to the density at which the continuous pore-channel structure characteristic of intermediate stage sintering breaks down. These transitions occurred over a much wider range, between 85 and 95\% TD, in the single-phase $\mathrm{Al}_{2} \mathrm{O}_{3}$. For example, abnormal grain growth and pore separation were observed at densities as low as $85 \%$ TD while the transition from a narrowing to a broadening pore distribution and the more rapid increase in $\mathrm{R}_{\mathrm{err}}(0)$ and $<\mathrm{R}>$ occurred between 90 and $95 \% \mathrm{TD}$. Hence, the $\mathrm{ZrO}_{2}$ addition delayed the onset of the transition from intermediate to final stage sintering, as in the MgO-doped system, ${ }^{10}$ thus, providing a narrower transition region and a more uniform transition. The narrower transition region is likely the result of the narrower grain size distribution in the $\mathrm{ZrO}_{2}$ containing samples.

Examination of the fracture surfaces of samples sintered at $1600^{\circ} \mathrm{C}$ for $300 \mathrm{~min}$, shown in Figure 16, provides additional information about the role of the $\mathrm{ZrO}_{2}$ additions. In sample 12-5, the majority of the $\mathrm{ZrO}_{2}$ grains, identified by the change in backscattering contrast, were located at $\mathrm{Al}_{2} \mathrm{O}_{3}$-grain junctions. The $\mathrm{ZrO}_{2}$ addition is, thus, expected to play a dominant role in preventing abnormal grain growth and pore-grain boundary separation, which is consistent with the observation of a fine-grained, dense $\mathrm{Al}_{2} \mathrm{O}_{3} / \mathrm{ZrO}_{2}$ composite in which all of the remaining porosity was situated on grain boundaries. On the other hand, exaggerated grain growth was observed in the single-phase $\mathrm{Al}_{2} \mathrm{O}_{3}$ (sample 13-8), along with many small pores which were trapped inside the large grains as a result of the abnormal grain growth. The large pores, however, were generally located on grain boundaries. 
In agreement with the earlier results of Lange et al. ${ }^{1.2}$ and $\mathrm{Zhao}$ and $\mathrm{Harmer},{ }^{5}$ the $\mathrm{ZrO}_{2}$ second phase addition was very effective in inhibiting grain growth during densification. The $\mathrm{ZrO}_{2}$ addition also slightly inhibited intermediate stage densification, in agreement with the results of Lange $e t$ $a l .,{ }^{1,2}$ while providing a slight acceleration of densification during final stage sintering, in agreement with the results of Zhao and Harmer. ${ }^{5}$ The $\mathrm{ZrO}_{2}$ addition ultimately resulted in a slightly lower final sintered density, however, in contrast to results ${ }^{5}$ on artificially-created bimodal pore distribution samples with $\mathrm{ZrO}_{2}$ additions.

The effect of the $\mathrm{ZrO}_{2}$ addition on microstructural evolution can be clearly seen by comparing sintering trajectories for the $\mathrm{Al}_{2} \mathrm{O}_{3} / \mathrm{ZrO}_{2}$ compacts and the single-phase $\mathrm{Al}_{2} \mathrm{O}_{3}$ compacts in grain size/pore size space. Trajectories of mean grain size normalized to the initial grain size, $\langle a\rangle\left|<a_{0}\right\rangle$, versus mean pore size normalized to the initial pore size, $\langle R\rangle\left\langle R_{0}\right\rangle$, are presented in Figure 17. A similar plot using $R_{\text {efr }}(0)$, which is more representative of the larger pores in the distribution, in place of the mean pore size is presented in Figure 18. It is evident from these figures that both systems exhibited complicated sintering trajectories. Furthermore, the second-phase $\mathrm{ZrO}_{2}$ addition provided effective inhibition of grain growth but caused dramatic increases in both mean pore size and $R_{\text {eff }}(0)$. It is also evident from the direct microstructural observation of pore/grain boundary separation only in the single-phase $\mathrm{Al}_{2} \mathrm{O}_{3}$ compacts, that the trajectories exhibited by the single-phase $\mathrm{Al}_{2} \mathrm{O}_{3}$ crossed into the pore/grain boundary separation regime discussed by Brook, ${ }^{15.16}$ while the flatter trajectories exhibited by the $\mathrm{Al}_{2} \mathrm{O}_{3} / \mathrm{ZrO}_{2}$ compacts prevented such separation.

A limited number of sintering models exist against which these experimental trajectories can be compared. A number of the early models of final stage sintering ${ }^{15-17}$ assumed geometric similitude between grain size and pore size. Hence, these models predict a mean pore size that scales with the increasing grain size. The observed effect of the $\mathrm{ZrO}_{2}$ addition on the grain size/pore size trajectories is not consistent with the predictions of these models. A recent Monte Carlo simulation of final stage sintering ${ }^{18}$ has yielded grain size/pore size trajectories that exhibit only a small increase in mean pore size, which occurs only over a very brief period during the initial portion of final stage 
sintering. ${ }^{19}$ Clearly the large and continuous increases in mean pore size observed in this study do not match the predictions of the Monte Carlo simulation of final stage sintering. Sintering models that take account of the statistical variations inherent in any real powder compact are also available. ${ }^{20.21}$ Fang and Palmour ${ }^{22}$ have used such a statistically based model to predict the grain size and pore size evolution during intermediate and final stage sintering of a Baikowski alumina (CR-10) that was of slightly smaller size $(0.13 \mu \mathrm{m}$ average particle diameter) than the powder used in the present investigation. Their results, plotted in terms of grain size/pore size trajectories in Figure 19, predict that a critical green density exists below which the mean pore size increases continuously during densification. For green densities above the critical value, an initial increase followed by a continuous decrease in the mean pore size is predicted. The results obtained in this study follow the general trends predicted by Fang and Palmour for their low green density (59.9\% TD) sample. However, the amount of increase in the mean pore size obtained for the single-phase alumina in this study was a factor of five higher than the model prediction for the low green density compact. Furthermore, the decrease in $<R>$ that was observed during the early stages of final stage sintering is not predicted by the model. This latter point is not surprising since the model predicts a relatively constant pore distribution width, and the decrease in $\langle R\rangle$ appears to result from the transition from a narrowing distribution during intermediate stage sintering to a broadening distribution during final stage sintering.

Zhao and Harmer ${ }^{5}$ have also investigated the effect of $\mathrm{ZrO}_{2}$ additions on final stage sintering of alumina compacts. Their modeling results suggest that the kinetic benefits associated with a reduced grain size almost always outweigh the thermodynamic gains achieved through grain growth. Their experimental results, obtained on compacts with an artificially imposed bimodal pore distribution, lend support to their model predictions. The results from the present study, obtained on compacts with naturally occurring, continuous pore distributions, appear to contradict the findings of Zhao and Harmer regarding the minor role played by thermodynamic aspects of grain growth. It is evident from the pore distributions in Figures 8 and 9 that the $\mathrm{ZrO}_{2}$ containing compacts maintained a lower population of large pores from the green state out to about $91 \%$ TD. Through 
this regime the mean grain sizes of both materials were essentially equivalent. Above $91 \%$ TD, accelerated grain growth was observed in the single-phase alumina, Figure 14, resulting in a much broader grain size distribution, Figure 15 . Pore size distributions for compacts slightly above $98 \%$ $\mathrm{TD}$, shown in Figure 10, indicate that, during the final stage of sintering, the $\mathrm{ZrO}_{2}$ addition resulted in a higher number of the larger pores. This is consistent with the more rapid increase in $R_{\text {efr }}(0)$ that was observed in the $\mathrm{ZrO}_{2}$ containing samples. Since the kinetics of pore removal should be accelerated by a smaller grain size, the increased volume of large pores in the high density $\mathrm{ZrO}_{2}$ containing samples suggests that the inhibited grain growth brought about by the $\mathrm{ZrO}_{2}$ addition adversely affected the thermodynamics of pore sintering.

The thermodynamic consequences of inhibited grain growth can be understood by considering the effect of pore coordination number on pore sinterability. As Lange ${ }^{7}$ has pointed out, consideration of pore coordination number leads to the conclusion that a critical pore/grain size ratio exists below which pores will sinter and above which pores are stable. From purely thermodynamic arguments a certain amount of grain growth can, therefore, be beneficial, leading to reduced pore coordination numbers. Hence, the sinterability of the large pores in the distribution should be inhibited by the reduced grain growth that resulted with the $\mathrm{ZrO}_{2}$ addition. The sinterability of small pores, on the other hand, should be enhanced by the $\mathrm{ZrO}_{2}$ addition, since inhibited grain growth should maintain contact between the pores and the grain boundaries and enhance the kinetics of pore shrinkage. Inhibited grain growth is, thus, expected to yield an enhanced removal of small pores and a reduced removal of large pores. This scenario is consistent with the results obtained in the present study.

\section{SUMMARY}

The microstructural parameters of pore radius and grain size were measured at various relative densities for single-phase alumina and alumina containing 12.4 vol.\% zirconia in an attempt to gain a better understanding of the effect of the second phase zirconia additive on microstructural 
evolution. Measurements of the pore distributions, obtained from the small-angle neutron scattering measurements, have identified a complex pore evolution process. During intermediate stage sintering, the pore channels with the smaller radii were preferentially removed, resulting in a narrowing of the pore distribution and a shift of the distribution peak and the average pore size to larger values. The effect of the zirconia addition during intermediate stage sintering was to increase the rate of removal of the pores at both ends of the distribution. This resulted in narrower pore distributions and larger average pore sizes.

During final stage sintering, the pore distributions began to broaden. The peak of the distributions and the average pore size decreased during the transition from intermediate to final stage sintering and then increased monotonically throughout the remainder of densification. Rapid increases in the moment representative of the higher end of the distributions, $R_{\text {eff }}(0)$, were observed throughout final stage sintering. The zirconia addition resulted in a higher percentage of the larger pores, as evidenced by the higher $R_{e f f}(0)$ values and the comparative volume distributions. This observation is thought to be due to the thermodynamic effects of grain growth inhibition by the zirconia.

Grain size/pore size trajectories have illustrated that the zirconia additions resulted in less grain growth but larger pore sizes, as measured by either $<R>$ or $R_{\text {eff }}(0)$. No sintering models capable of predicting the microstructural trajectories obtained in the study were found. One can, therefore, conclude that development of improved sintering models is necessary if one hopes to be able to predict the pore evolution process in practical powder compacts.

\section{ACKNOWLEDGEMENT}

This work was supported by the U.S. Department of Energy, Office of Basic Energy Sciences under Grant No. DE-FG05-84ER45063. 


\section{REFERENCES}

1. F.F. Lange and M.M. Hirlinger, "Hindrance of Grain Growth in $\mathrm{Al}_{2} \mathrm{O}_{3}$ by $\mathrm{ZrO}_{2}$ Inclusions," J. Am. Ceram. Soc., 67 [3] 164-68 (1984).

2. F.F. Lange, T. Yamaguchi, B.I. Davis, and P.E.D. Morgan," Effect of $\mathrm{ZrO}_{2}$ Inclusions on the Sinterability of $\mathrm{Al}_{2} \mathrm{O}_{3}$," J. Am. Ceram. Soc., 71 [6] 446-48 (1988).

3. C.H. Hsueh, A.G. Evans, and R.C. Coble, "Microstructural Development During Final/Intermediate Stage Sintering-I. Pore/Grain Boundary Separation," Acta. Met., 30 [7] 1269-79 (1982).

4. M.A. Spears and A.G. Evans, "Tbid-II. Grain and Pore Coarsening, "Acta. Met., 30 [7] 1281-89 (1982).

5. J. Zhao and M.P. Harmer, "Effect of Pore Distribution on Microstructure Development: II. First- and Second-Generation Pores," J. Am. Ceram. Soc., 71 [7] 530-39 (1988).

6. W.D. Kingery and B. Francois, "Sintering of Crystalline Oxides, I. Interactions Between Grain Boundaries and Pores," pp. 471-98 in Sintering and Related Phenomena, Edited by G.C. Kuczynski, N.A. Hooton, and G.F. Gibbon, Gordon Breach, New York, 1967.

7. F.F. Lange, "Sinterability of Agglomerated Powders," J. Am. Ceram. Soc., 67 [2] 83-88 (1984).

8. J. Zheng and J.S. Reed, "The Different Roles of Forming and Sintering on Densification of Powder Compacts," Am. Ceram. Soc. Bull., 71 [9] 1410-16 (1992).

9. S. Krueger, G.G. Long, and R.A. Page, "Characterization of the Densification of Alumina by Multiple Small-Angle Neutron Scattering," Acta Cryst., A47, 282-90 (1991). 
10. G.G. Long, S. Krueger, and R.A. Page, "The Effect of Green Density and the Role of Magnesium Oxide Additive on the Densification of Alumina Measured by Small-Angle Neutron Scattering," J. Am. Ceram. Soc., 74 [7] 1578-84 (1991).

11. S. Krueger, G.G. Long, D.R. Black, D. Minor, P.R. Jemian, G.W. Nieman, and R.A. Page, "Evolution of the Pore Size Distribution in Final-Stage Sintering of Alumina Measured by Small-Angle X-ray Scattering," J. Am. Ceram. Soc., 74 [10] 2538-46 (1991).

12. N.F. Berk and K.A. Hardman-Rhyne, "Analysis of SAS Data Dominated by Multiple Scattering," J. Appl. Crystallogr., 21 [6] 645-51 (1988).

13. G. Porod, "The Small-Angle Scattering of X-Rays by Dense Colloidal Systems," Kolloid Z, 125 [1] $51-57$ (1952).

14. K.A. Hardman-Rhyne and N.F. Berk, "Characterization of Alumina Powder Using Small-Angle Neutron Scattering, II: Experiment," J. Appl. Crystallogr. 18 [6] 473-79 (1985).

15. R.J. Brook, "Pore-Grain Boundary Interactions and Grain Growth," J. Am. Ceram. Soc., 52 [1] 56-67 (1969).

16. R.J. Brook, "Controlled Grain Growth," pp. 331-64 in Treatise on Materials Science and Technology, Vol. 9, Edited by F.F.Y. Wang. Academic Press, New York, 1976.

17. W.D. Kingery and B. Francois, "Grain Growth in Porous Compacts," J. Am. Ceram. Soc., 48 [10] 546-47 (1965).

18. G.N. Hassold, I-W.Chen, and D.J. Srolovitz, "Computer Simulation of Final-Stage Sintering" I, Model, Kinetics, and Microstructure," J. Am. Ceram. Soc., 73 [10] 2857-64 (1990).

19. I-W. Chen, G.N. Hassold, and D.J. Srolovitz, "Computer Simulation of Final Stage Sintering: II, Influence of Initial Pore Size," J. Am Ceram. Soc., 73 [10] 2865-72 (1990). 
20. G.C. Kuczynski, "Statistical Theory of Sintering," Z. Metallkunde, 67 [9] 606-10 (1976).

21. T-T. Fang and H. Palmour, III, "Useful Extensions of the Statistical Theory of Sintering," Ceram. Int., 15 [6] 329-35 (1989).

22. T-T. Fang and H. Palmour, III, "Nondestructive Characterization of Morphological Development in Sintered Powder Compacts," Ceram. Int., 16 [2] 63-71 (1990). 
Table 1. MSANS Results for the 12.4 vol.\% Zirconia-Alumina Samples.

\begin{tabular}{|c|c|c|c|c|c|c|c|c|c|}
\hline \multirow{2}{*}{$\begin{array}{c}\text { Sample } \\
\text { No. }\end{array}$} & \multirow{2}{*}{$\begin{array}{l}\text { Sintering Times } \\
\text { at } 1600^{\circ} \mathrm{C}(\mathrm{min})\end{array}$} & \multirow{2}{*}{$\begin{array}{l}\text { Volumetric* } \\
\text { Density } \\
\text { (\% TD) }\end{array}$} & \multicolumn{2}{|c|}{ Wavelength (nm) } & \multirow[b]{2}{*}{$\mathrm{R}_{\mathrm{efr}}(0)(\mu \mathrm{m})$} & \multicolumn{2}{|c|}{$\bar{z}$} & \multicolumn{2}{|c|}{ Phase Shift } \\
\hline & & & Min & $\operatorname{Max}$ & & Min & $\operatorname{Max}$ & Min & $\operatorname{Max}$ \\
\hline $12-6$ & green body & 53.8 & 0.6 & 1.0 & $0.15 \pm 0.02$ & 118 & 206 & 0.15 & 0.16 \\
\hline $12-4$ & no soak & 85.8 & 0.8 & 1.0 & $0.23 \pm 0.002$ & 62 & 77 & 0.21 & 0.23 \\
\hline $12-1$ & 7 & 91.1 & 0.8 & 1.0 & $0.25 \pm 0.004$ & 46 & 69 & 0.24 & 0.29 \\
\hline $12-2$ & 30 & 96.6 & 0.8 & 1.2 & $0.42 \pm 0.002$ & 29 & 64 & 0.39 & 0.58 \\
\hline $12-9$ & 120 & 98.1 & 1.4 & 2.0 & $0.79 \pm 0.04$ & 108 & 171 & 1.54 & 1.73 \\
\hline $12-5$ & 300 & 98.4 & 1.4 & 2.0 & $1.26 \pm 0.05$ & 114 & 257 & 2.12 & 3.33 \\
\hline
\end{tabular}

* Theoretical density is $4.24 \mathrm{~g} / \mathrm{cm}^{3}$. 
Table 2. Porod Results for the 12.4 vol.\% Zirconia Samples.

\begin{tabular}{|c|c|c|c|}
\hline $\begin{array}{c}\text { Sample } \\
\text { No. }\end{array}$ & $\begin{array}{c}\text { Volumetric Density } \\
(\% \mathrm{TD})\end{array}$ & $\begin{array}{c}\text { Pore Surface Area } \\
\left(\mathrm{x} 10^{4} \mathrm{~cm}^{-1}\right)\end{array}$ & $\begin{array}{c}\mathrm{R}_{\text {eff }}(\infty) \\
(\mu \mathrm{m})\end{array}$ \\
\hline $12-6$ & 53.8 & $19.3 \pm 0.2$ & $0.072 \pm 0.001$ \\
$12-4$ & 85.8 & $2.15 \pm 0.02$ & $0.198 \pm 0.001$ \\
$12-1$ & 91.1 & $1.21 \pm 0.006$ & $0.220 \pm 0.001$ \\
$12-2$ & 96.6 & $0.36 \pm 0.003$ & $0.287 \pm 0.002$ \\
$12-9$ & 98.1 & $0.11 \pm 0.001$ & $0.513 \pm 0.004$ \\
$12-5$ & 98.4 & $0.069 \pm 0.0003$ & $0.709 \pm 0.003$ \\
\hline
\end{tabular}


Table 3. Number Weighted Pore Size Distribution Parameters for the $\mathrm{Al}_{2} \mathrm{O}_{3}$ and $\mathrm{Al}_{2} \mathrm{O}_{3} / \mathrm{ZrO}_{2}$ Compacts.

\begin{tabular}{||c|c|c|c|c||}
\hline $\begin{array}{c}\text { Sample } \\
\text { No. }\end{array}$ & $\begin{array}{c}\text { Volumetric } \\
\text { Density } \\
(\% \mathrm{TD})\end{array}$ & $\begin{array}{c}<\mathrm{R}> \\
(\mu \mathrm{m})\end{array}$ & $\begin{array}{c}\mathrm{R}_{\text {mode }} \\
(\mu \mathrm{m})\end{array}$ & $\beta$ \\
\hline 12.4 vol.\% $\mathrm{ZrO}_{2}$ - Alumina & \multicolumn{3}{|c||}{} \\
\hline $12-6$ & 53.8 & 0.017 & 0.0055 & 0.86 \\
$12-4$ & 85.8 & 0.15 & 0.12 & 0.39 \\
$12-1$ & 91.1 & 0.17 & 0.14 & 0.36 \\
$12-2$ & 96.6 & 0.13 & 0.075 & 0.62 \\
$12-9$ & 98.1 & 0.22 & 0.11 & 0.66 \\
$12-5$ & 98.4 & 0.23 & 0.094 & 0.76 \\
\hline Pure Alumina & \multicolumn{3}{|c|}{} \\
\hline $13-2$ & 56.5 & 0.019 & 0.0057 & 0.89 \\
$13-3$ & 67.0 & 0.035 & 0.012 & 0.75 \\
$13-4$ & 79.1 & 0.044 & 0.022 & 0.67 \\
$13-5$ & 85.4 & 0.053 & 0.029 & 0.64 \\
$13-1$ & 90.8 & 0.069 & 0.038 & 0.63 \\
$13-6$ & 94.6 & 0.062 & 0.027 & 0.74 \\
$13-7$ & 97.1 & 0.094 & 0.040 & 0.76 \\
$13-8$ & 98.9 & 0.15 & 0.068 & 0.73 \\
\hline
\end{tabular}


Table 4. Grain Size Data for $\mathrm{Al}_{2} \mathrm{O}_{3}$ and $\mathrm{Al}_{2} \mathrm{O}_{3} / \mathrm{ZrO}_{2}$ Compacts.

\begin{tabular}{|c|c|c|c|c|}
\hline \multirow{2}{*}{$\begin{array}{c}\text { Sample } \\
\text { No. }\end{array}$} & \multirow{2}{*}{$\begin{array}{l}\text { Sintering } \\
\text { Condition }\end{array}$} & \multirow{2}{*}{$\begin{array}{c}\text { Volumetric* } \\
\text { Density } \\
\text { (\% TD) }\end{array}$} & \multicolumn{2}{|c|}{ Mean Grain Size $(\mu \mathrm{m})$} \\
\hline & & & $\mathrm{Al}_{2} \mathrm{O}_{3}$ & $\mathrm{ZrO}_{2}$ \\
\hline \multicolumn{5}{|c|}{12.4 vol. $\% \mathrm{ZrO}_{2}$ - Alumina } \\
\hline $\begin{array}{l}12-4 \\
12-1 \\
12-2 \\
12-5 \\
\end{array}$ & $\begin{array}{c}1600^{\circ} \mathrm{C} / \text { no soak } \\
1600^{\circ} \mathrm{C} / 7 \mathrm{~min} . \\
1600^{\circ} \mathrm{C} / 30 \mathrm{~min} . \\
1600^{\circ} \mathrm{C} / 300 \mathrm{~min} .\end{array}$ & $\begin{array}{l}85.8 \\
91.1 \\
96.6 \\
98.4 \\
\end{array}$ & $\begin{array}{l}0.46 \pm 0.14 \\
0.55 \pm 0.17 \\
0.65 \pm 0.24 \\
1.05 \pm 0.38\end{array}$ & $\begin{array}{l}0.35 \pm 0.07 \\
0.33 \pm 0.08 \\
0.31 \pm 0.07 \\
0.43 \pm 0.13\end{array}$ \\
\hline \multicolumn{5}{|l|}{ Pure Alumina } \\
\hline $\begin{array}{l}13-4 \\
13-5 \\
13-1 \\
13-6 \\
13-7 \\
13-8\end{array}$ & $\begin{array}{c}1540^{\circ} \mathrm{C} / \text { no soak } \\
1570^{\circ} \mathrm{C} / \text { no soak } \\
1600^{\circ} \mathrm{C} / \text { no soak } \\
1600^{\circ} \mathrm{C} / 7 \text { min. } \\
1600^{\circ} \mathrm{C} / 30 \mathrm{~min} . \\
1600^{\circ} \mathrm{C} / 300 \mathrm{~min} .\end{array}$ & $\begin{array}{l}79.1 \\
85.4 \\
90.8 \\
94.6 \\
97.1 \\
98.9\end{array}$ & $\begin{array}{l}0.34 \pm 0.19 \\
0.33 \pm 0.27 \\
0.52 \pm 0.28 \\
0.72 \pm 0.45 \\
1.05 \pm 0.70 \\
1.80 \pm 1.28\end{array}$ & $\begin{array}{l}-- \\
-- \\
--- \\
--- \\
-- \\
--\end{array}$ \\
\hline
\end{tabular}

* Theoretical Density: $4.24 \mathrm{~g} / \mathrm{cm}^{3}$ for 12.4 vol. $\% \mathrm{ZrO}_{2} / \mathrm{Al}_{2} \mathrm{O}_{3} ; 3.98 \mathrm{~g} / \mathrm{cm}^{3}$ for pure $\mathrm{Al}_{2} \mathrm{O}_{3}$. 


\section{LIST OF FIGURES}

Figure 1. Relative density versus sintering time at $1600^{\circ} \mathrm{C}$ for both single-phase alumina and 12.4 vol.\% $\mathrm{ZrO}_{2}$-containing alumina samples sintered at $1600^{\circ} \mathrm{C}$.

Figure 2. Scanning electron micrographs of 12.4 vol. $\% \mathrm{ZrO}_{2}$-containing alumina samples at different relative densities: $12-4$ (85.8\% TD), 12-1 (91.1\% TD), 12-2 (96.6\% TD), and $12-5$ (98.4\% TD).

Figure 3. Scanning electron micrographs of single-phase alumina samples at different relative densities: $13-4$ (79.1\% TD), 13-5 (85.4\% TD), 13-1 (90.8\% TD), 13-6 (94.6\% TD), $13-7$ (97.1\% TD) and 13-8 (98.9\% TD).

Figure 4. Effective pore radius, $R_{\text {efr }}(0)$, versus relative density for both series of samples.

Figure 5. Effective pore radius, $R_{\text {eff }}(0)$, versus sintering time at $1600^{\circ} \mathrm{C}$ for both series of samples.

Figure 6. Evolution of the pore volume size distributions during densification of the $\mathrm{Al}_{2} \mathrm{O}_{3} / \mathrm{ZrO}_{2}$ compact.

Figure 7. Evolution of the pore volume size distributions during densification of the single-phase $\mathrm{Al}_{2} \mathrm{O}_{3}$ compact.

Figure 8. Pore volume size distributions for the $\mathrm{Al}_{2} \mathrm{O}_{3} / \mathrm{ZrO}_{2}$ and the single-phase $\mathrm{Al}_{2} \mathrm{O}_{3}$ green bodies.

Figure 9. Pore volume size distributions for the $\mathrm{Al}_{2} \mathrm{O}_{3} / \mathrm{ZrO}_{2}$ and the single-phase $\mathrm{Al}_{2} \mathrm{O}_{3}$ compacts at $\sim 91 \%$ TD.

Figure 10. Pore volume size distributions for the $\mathrm{Al}_{2} \mathrm{O}_{3} / \mathrm{ZrO}_{2}$ and the single-phase $\mathrm{Al}_{2} \mathrm{O}_{3}$ compacts at between 98 and 99\% TD.

Figure 11. Mean pore size, $<\mathrm{R}>$, versus relative density for both series of samples.

Figure 12. $R_{\text {mode }}$ versus relative density for both series of samples.

Figure 13. Mean grain size of both $\mathrm{Al}_{2} \mathrm{O}_{3}$ and $\mathrm{ZrO}_{2}$ phases as a function of sintering time at $1600^{\circ} \mathrm{C}$ for both series of samples.

Figure 14. Mean grain size versus relative density for both series of samples.

Figure 15. Grain size distribution histograms for $12-5$ and $13-8$ samples sintered at $1600^{\circ} \mathrm{C}$ for $300 \mathrm{~min}$.

Figure 16. Fracture surfaces of $12-5$ and $13-8$ samples sintered at $1600^{\circ} \mathrm{C}$ for $300 \mathrm{~min}$.

Figure 17. Grain size/mean pore size trajectories for the $\mathrm{Al}_{2} \mathrm{O}_{3} / \mathrm{ZrO}_{2}$ and the single-phase $\mathrm{Al}_{2} \mathrm{O}_{3}$ samples. Both the mean grain size, $\langle a\rangle$, and the mean pore size, $\langle\mathrm{R}\rangle$, are normalized to their initial values in the green compact. 
Figure 18. Grain size/effective pore size trajectories for the $\mathrm{Al}_{2} \mathrm{O}_{3} / \mathrm{ZrO}_{2}$ and the single-phase $\mathrm{Al}_{2} \mathrm{O}_{3}$ samples. Both the mean grain size, $<a>$, and the effective pore size, $\mathrm{R}_{\mathrm{eff}}(0)$, are normalized to their initial values in the green compact.

Figure 19. Grain size/mean pore size trajectories predicted for single-phase $\mathrm{Al}_{2} \mathrm{O}_{3}$ compacts by Fang and Palmour ${ }^{22}$ using a statistical sintering model. 


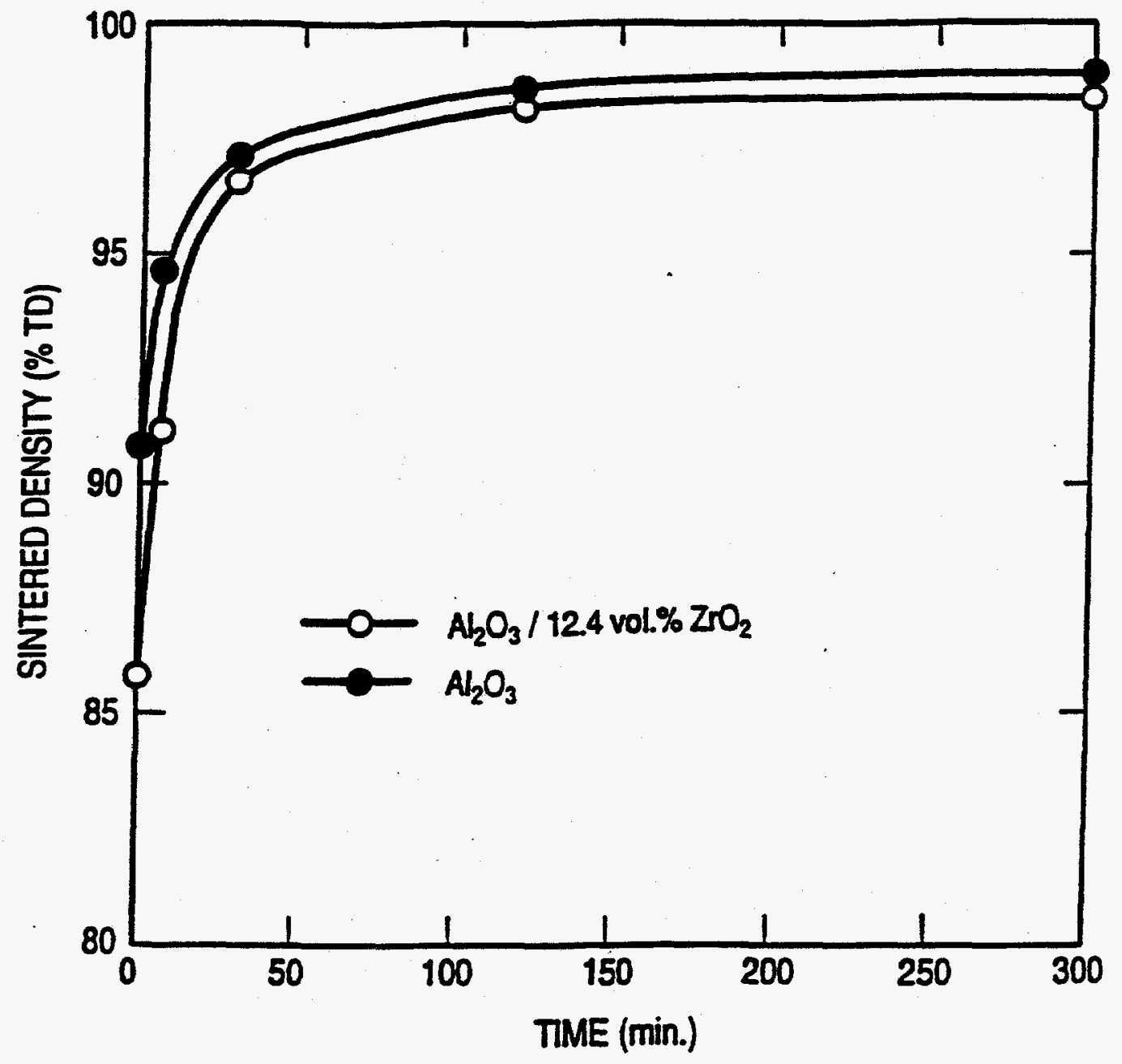

Figure 1. Relative density versus sintering time at $1600^{\circ} \mathrm{C}$ for both single-phase alumina and $12.4 \mathrm{vol} \% \mathrm{ZrO}_{2}$-containing alumina samples sintered at $1600^{\circ} \mathrm{C}$. 

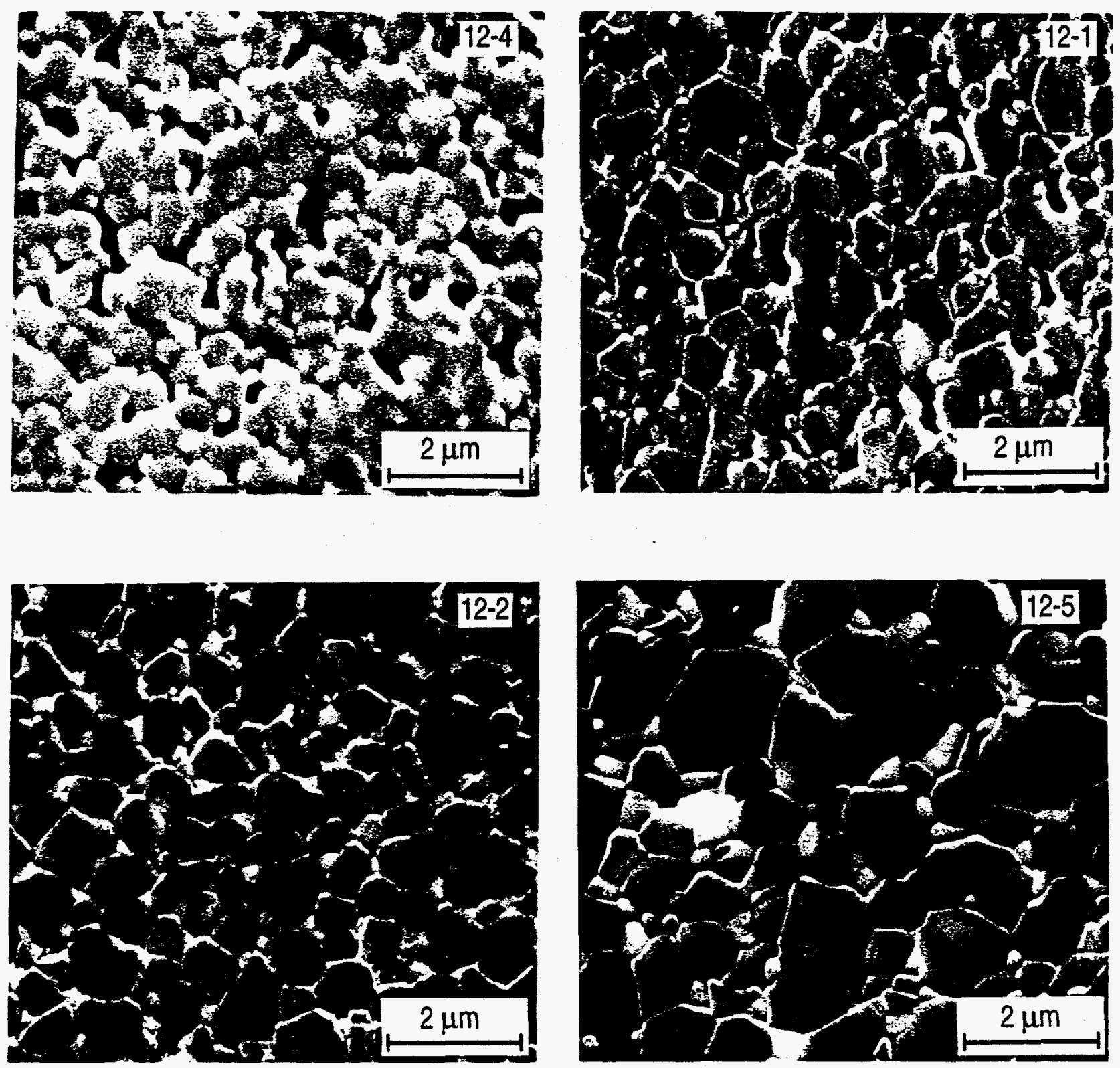

Figure 2. Scanning electron micrographs of 12.4 vol.\% $\mathrm{ZrO}_{2}$-containing alumina samples at different relative densities: $12-4$ (85.8\% TD), $12-1$ (91.1\% TD), $12-2$ (96.6\% TD), and $12-5$ (98.4\% TD). 

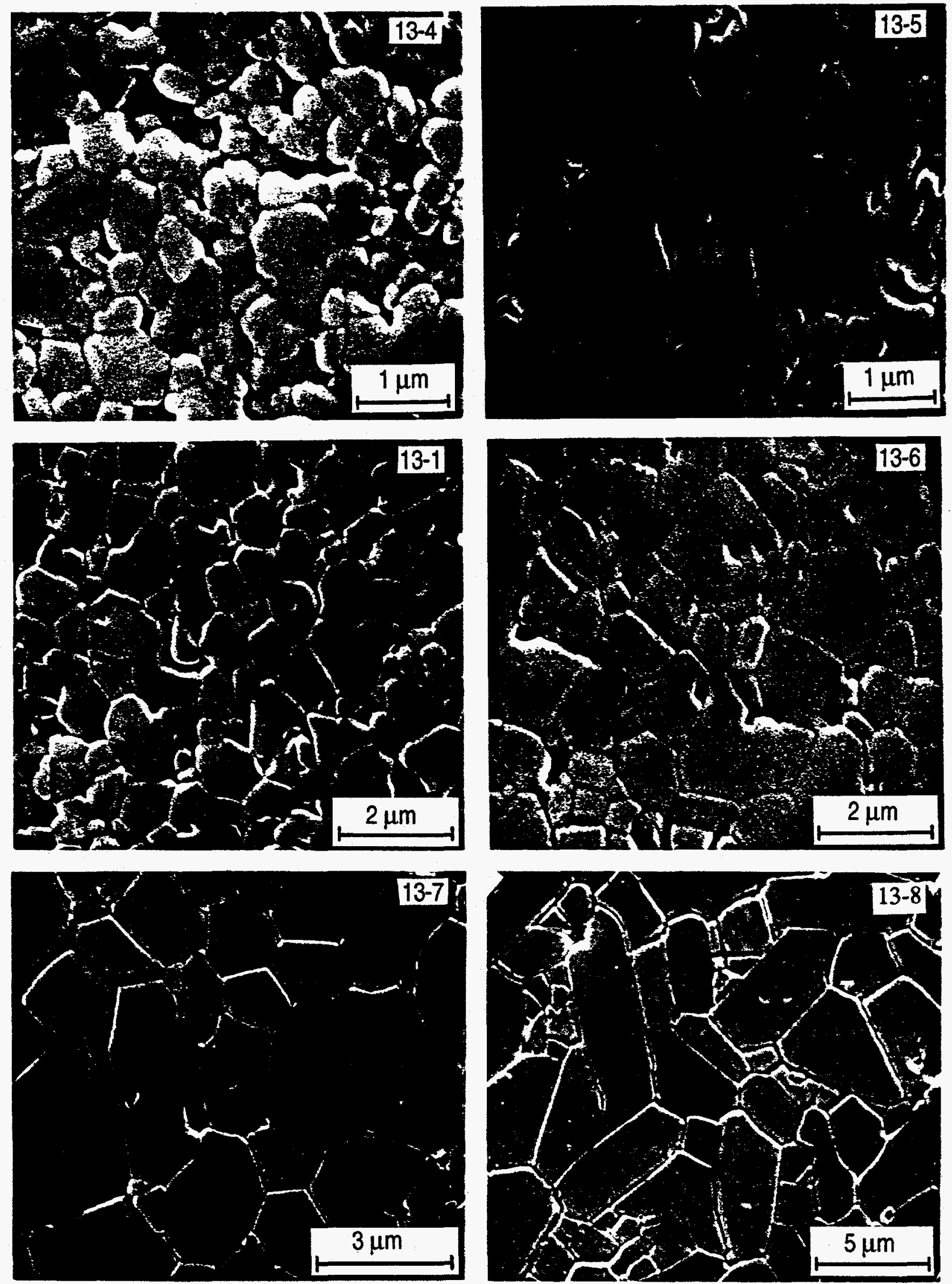

Figure 3. Scanning electron micrographs of single-phase alumina samples at different relative densities: 13-4 (79.1\% TD), 13-5 (85.4\% TD), 13-1 (90.8\% TD), 13-6 (94.6\% TD), 13-7 (97.1\% TD) and $13-8$ (98.9\% TD). 


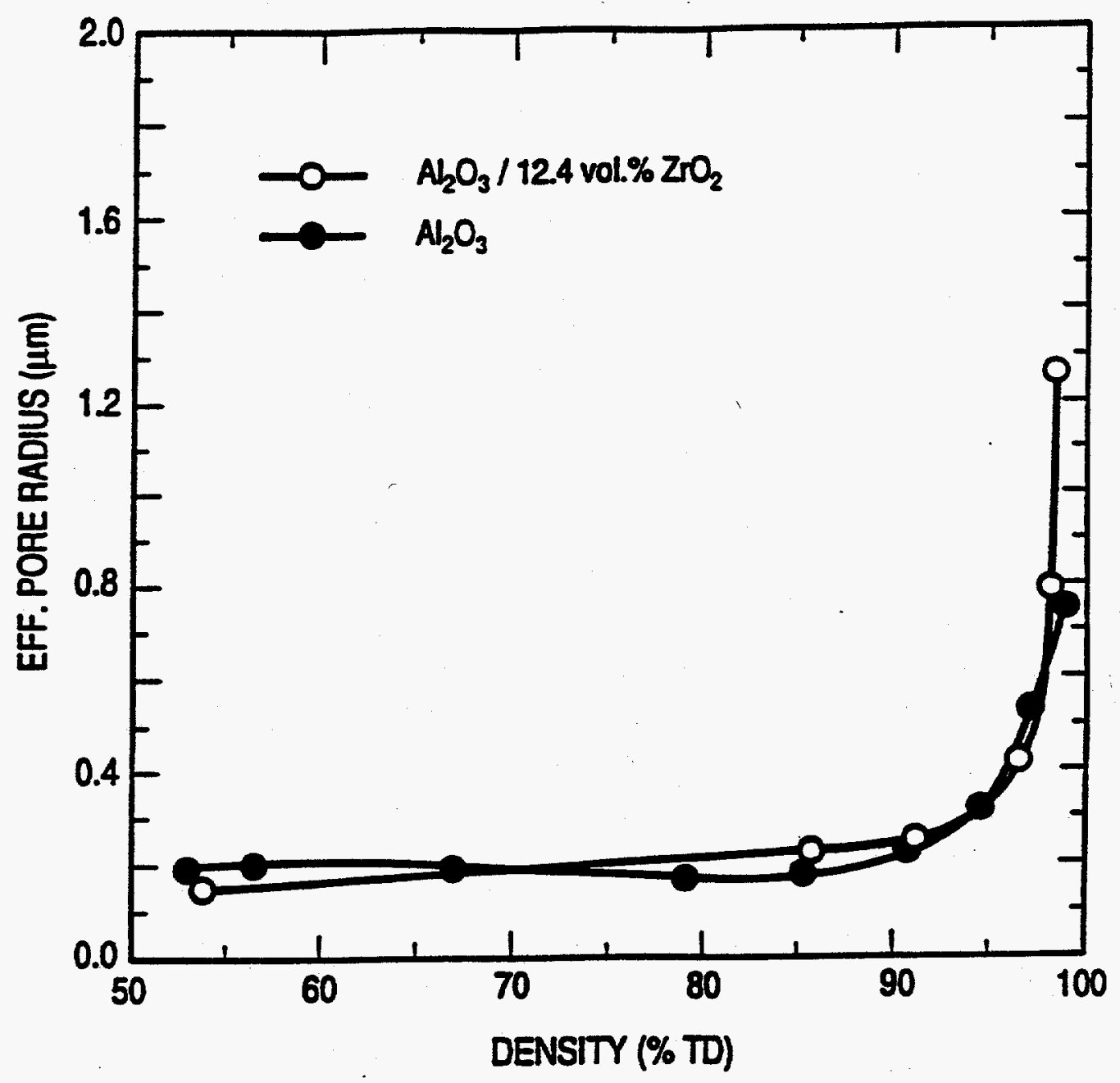

Figure 4. Effective pore radius, $R_{\text {eff }}(0)$, versus relative density for both series of samples. 


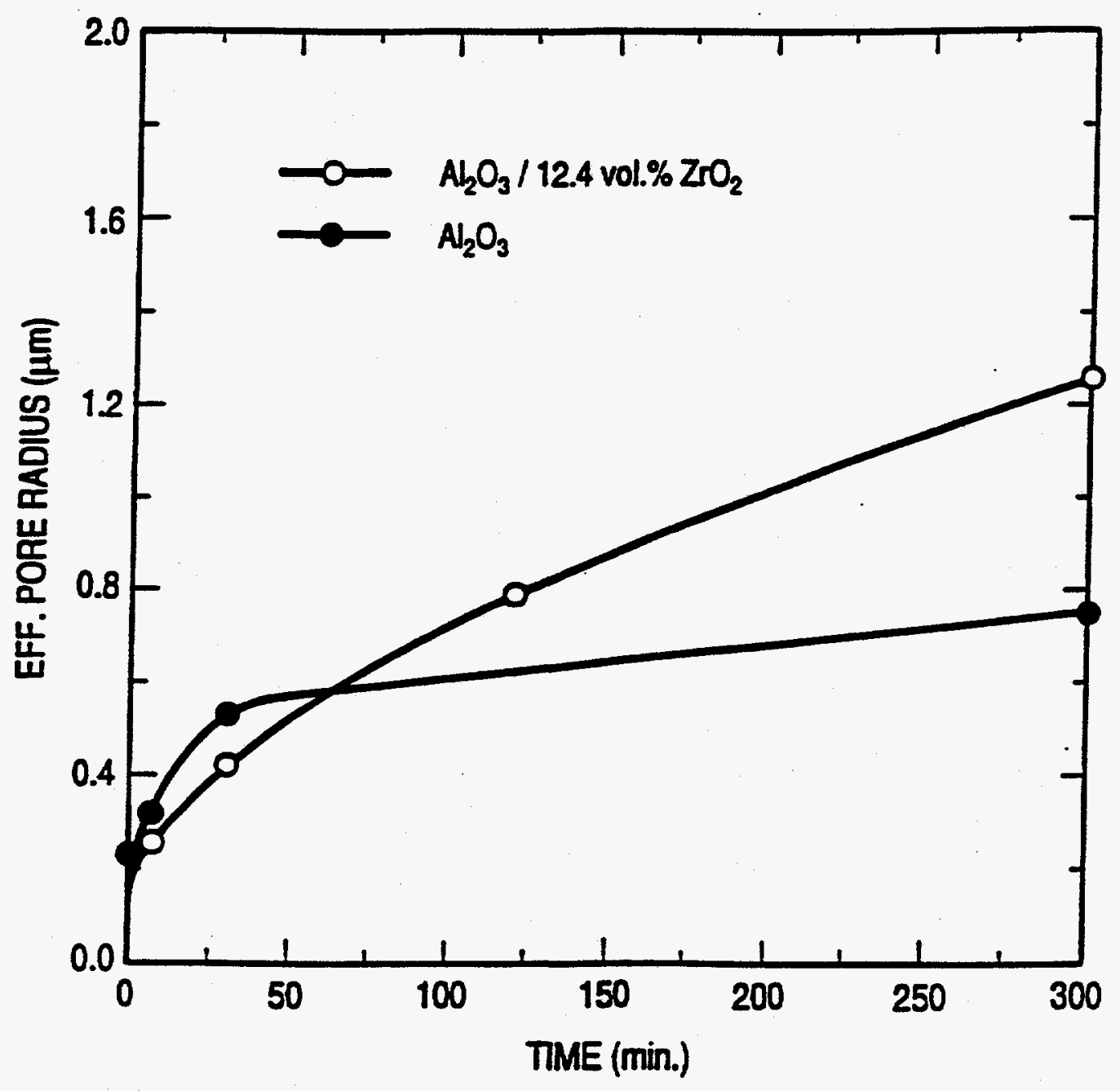

Figure 5. Effective pore radius, $R_{\text {eff }}(0)$, versus sintering time at $1600^{\circ} \mathrm{C}$ for both series of samples. 

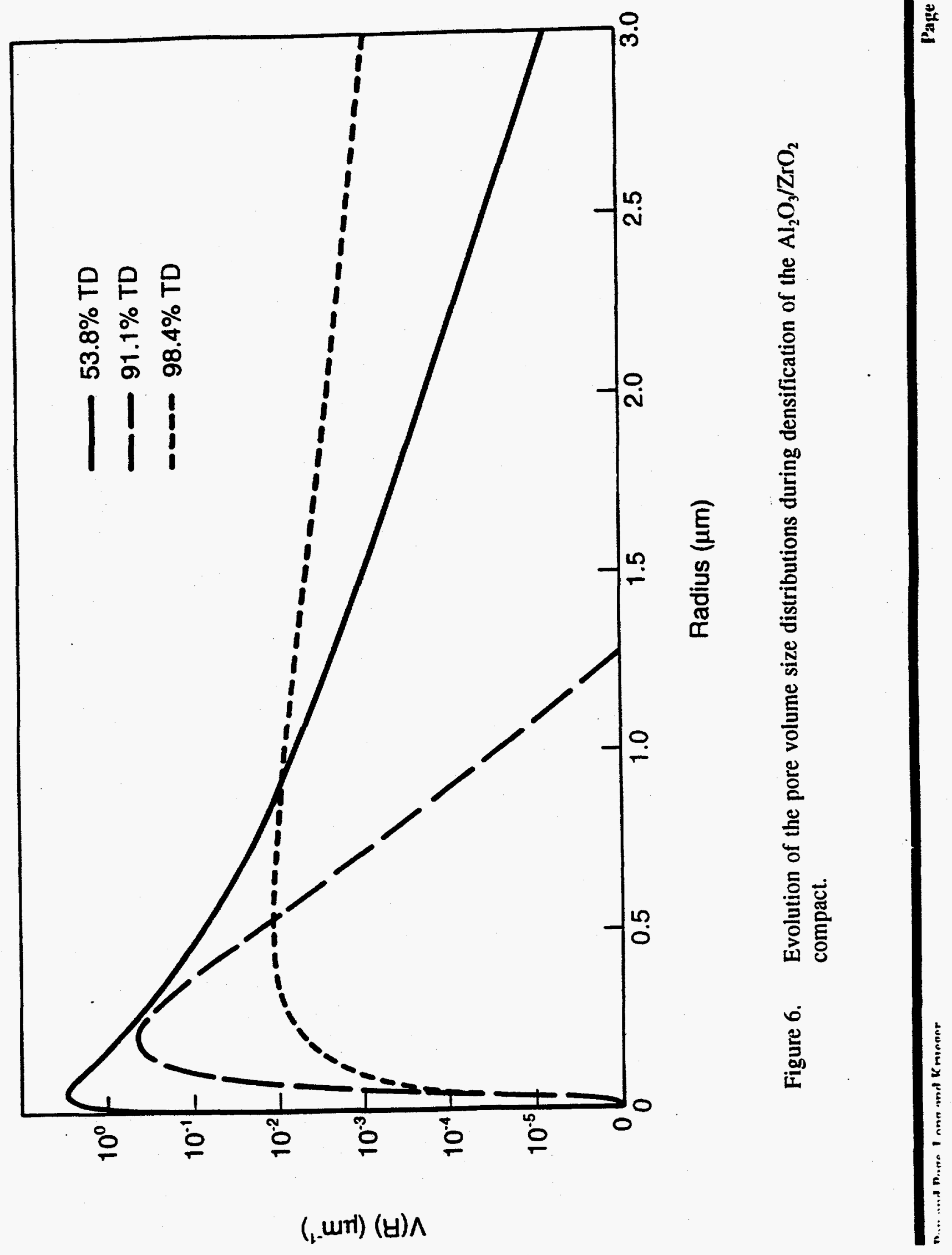


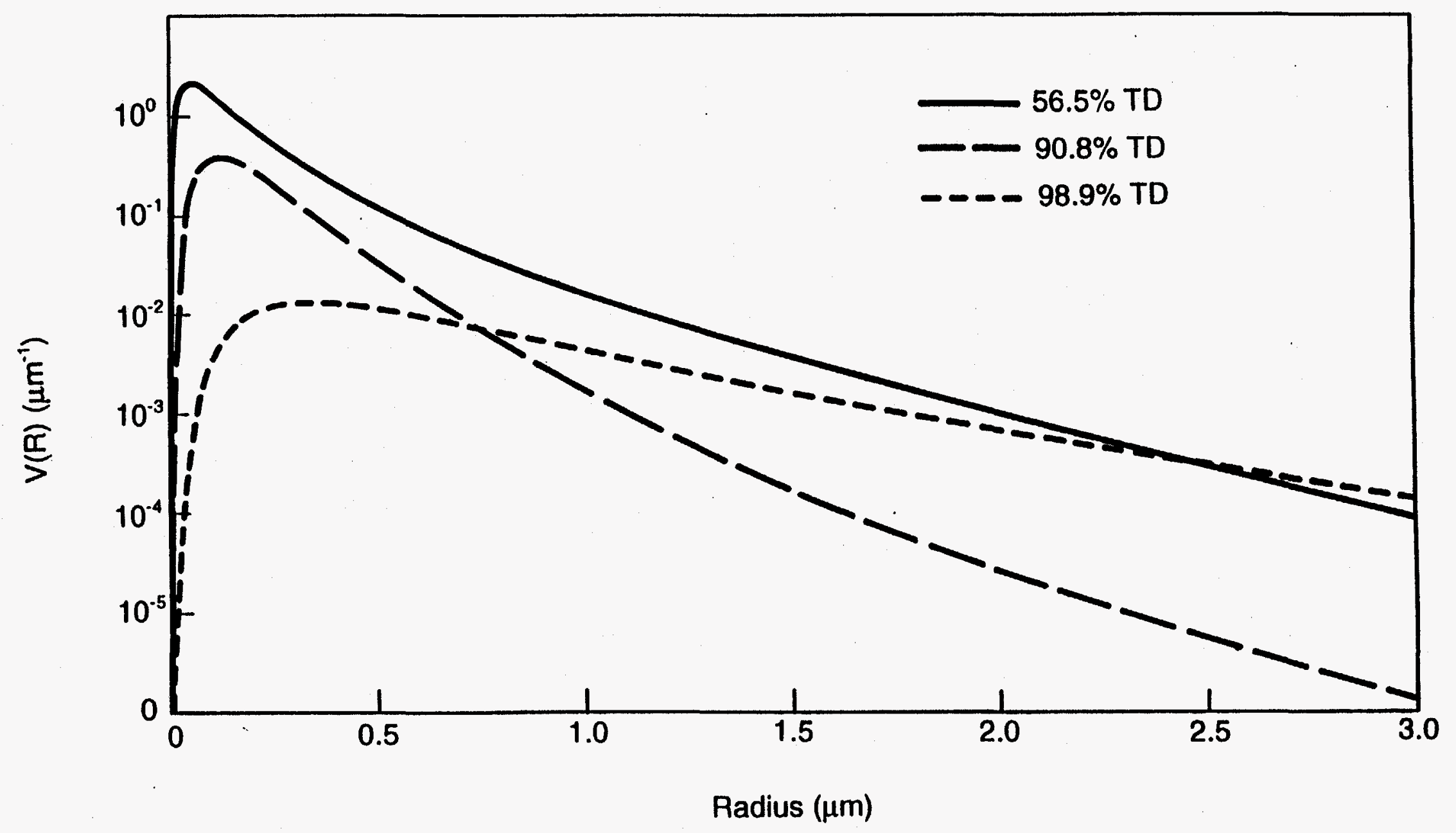

Figure 7. Evolution of the pore volume size distributions during densification of the single-phase $\mathrm{Al}_{2} \mathrm{O}_{3}$ compact. 


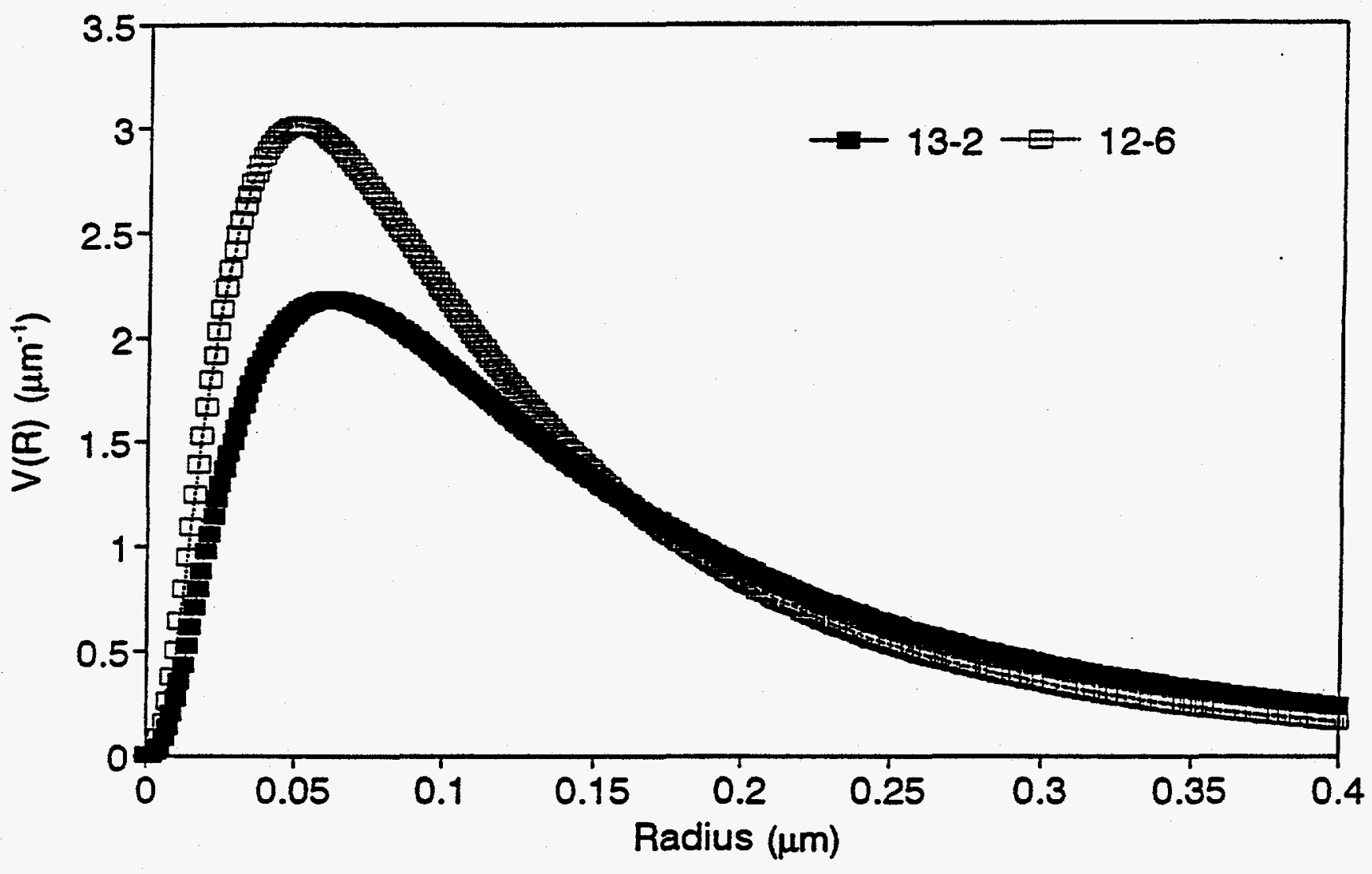

Figure 8. Pore volume size distributions for the $\mathrm{Al}_{2} \mathrm{O}_{3} / \mathrm{ZrO}_{2}$ and the single-phase $\mathrm{Al}_{2} \mathrm{O}_{3}$ green bodies. 


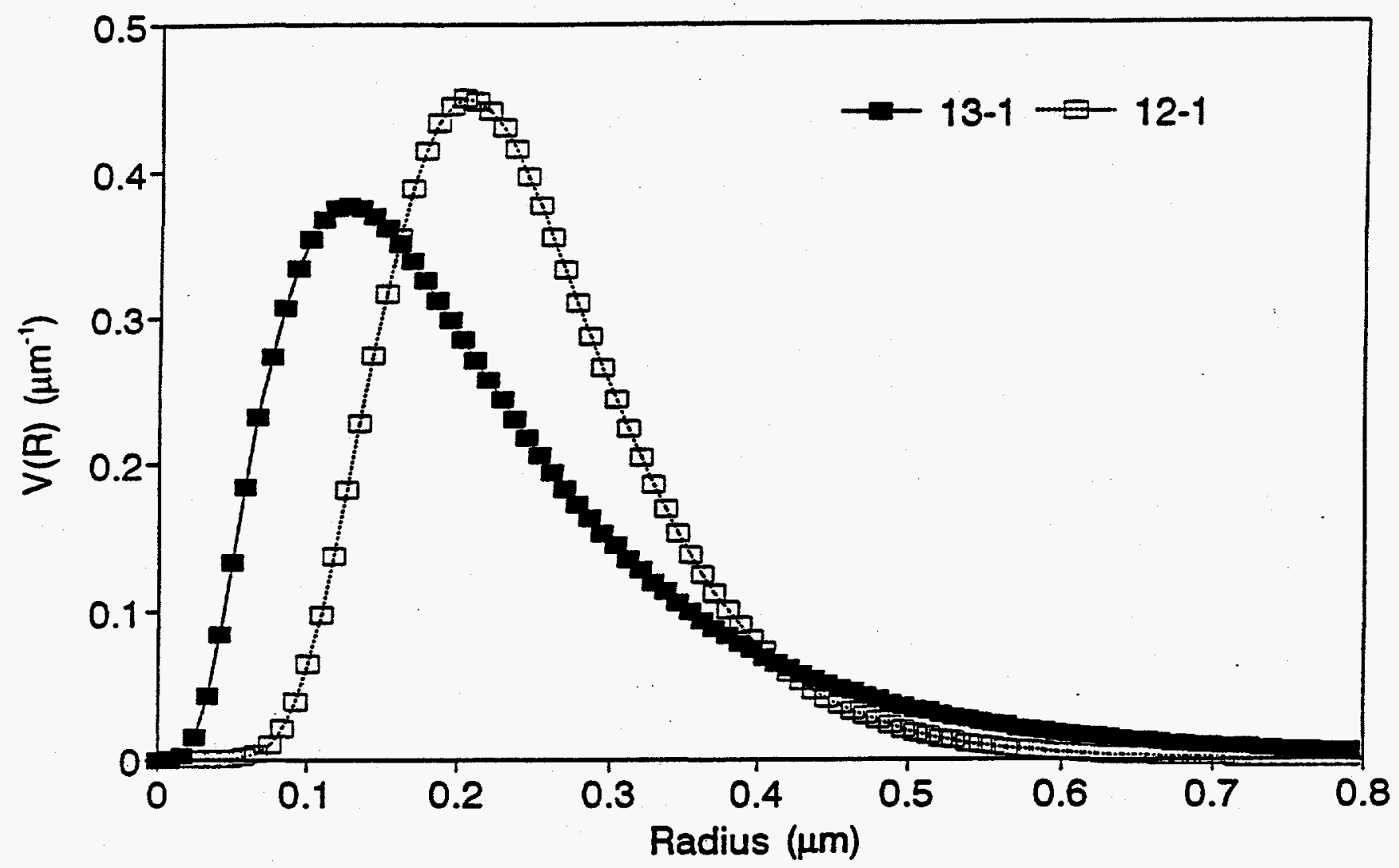

Figure 9. Pore volume size distributions for the $\mathrm{Al}_{2} \mathrm{O}_{3} / \mathrm{ZrO}_{2}$ and the single-phase $\mathrm{Al}_{2} \mathrm{O}_{3}$ compacts at $\sim 91 \% \mathrm{TD}$. 


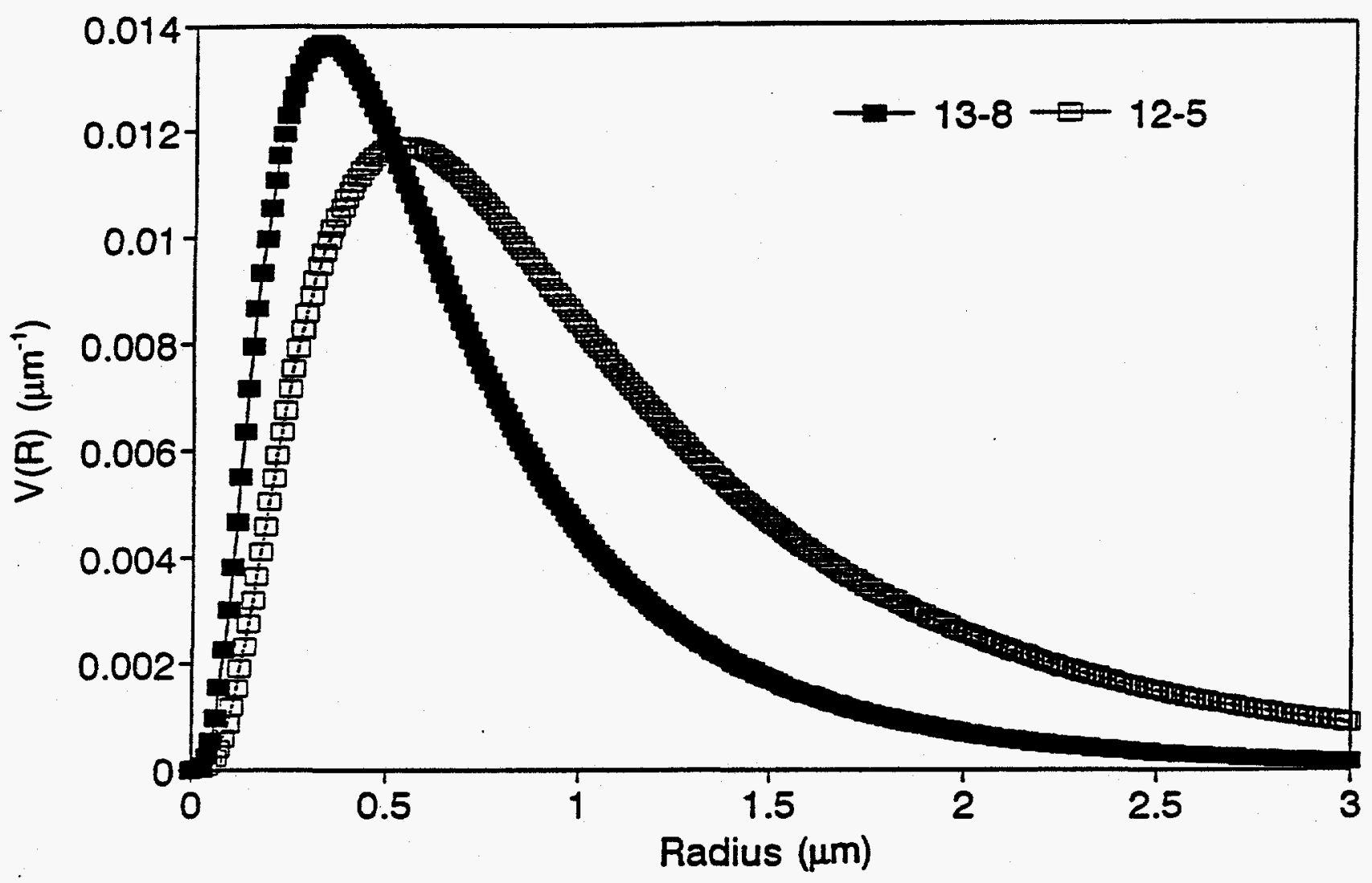

Figure 10. Pore volume size distributions for the $\mathrm{Al}_{2} \mathrm{O}_{3} / \mathrm{ZrO}_{2}$ and the single-phase $\mathrm{Al}_{2} \mathrm{O}_{3}$ compacts at between 98 and $99 \%$ TD. 


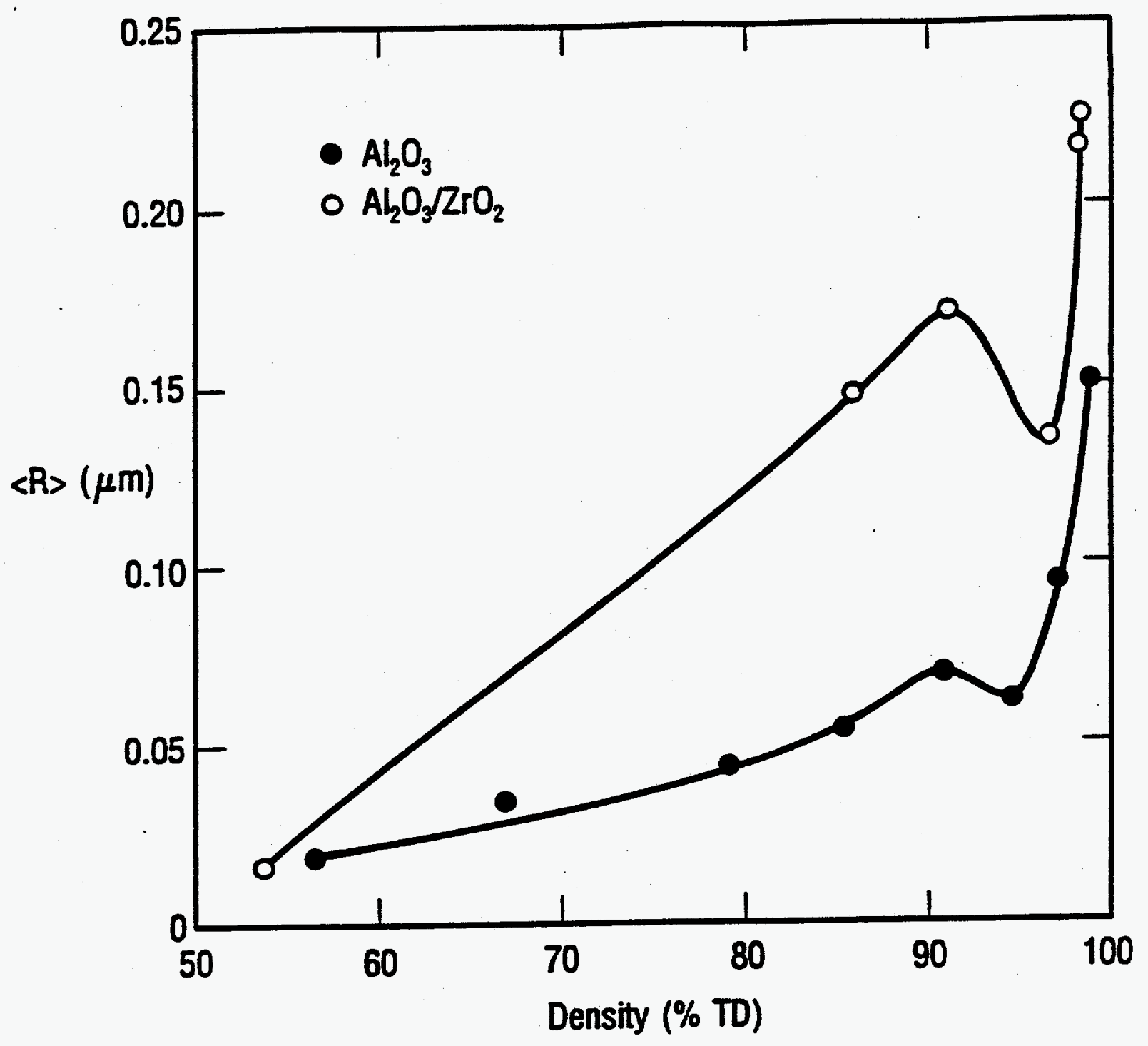

Figure 11. Mean pore size, $\langle\mathrm{R}>$, versus relative density for both series of samples. 


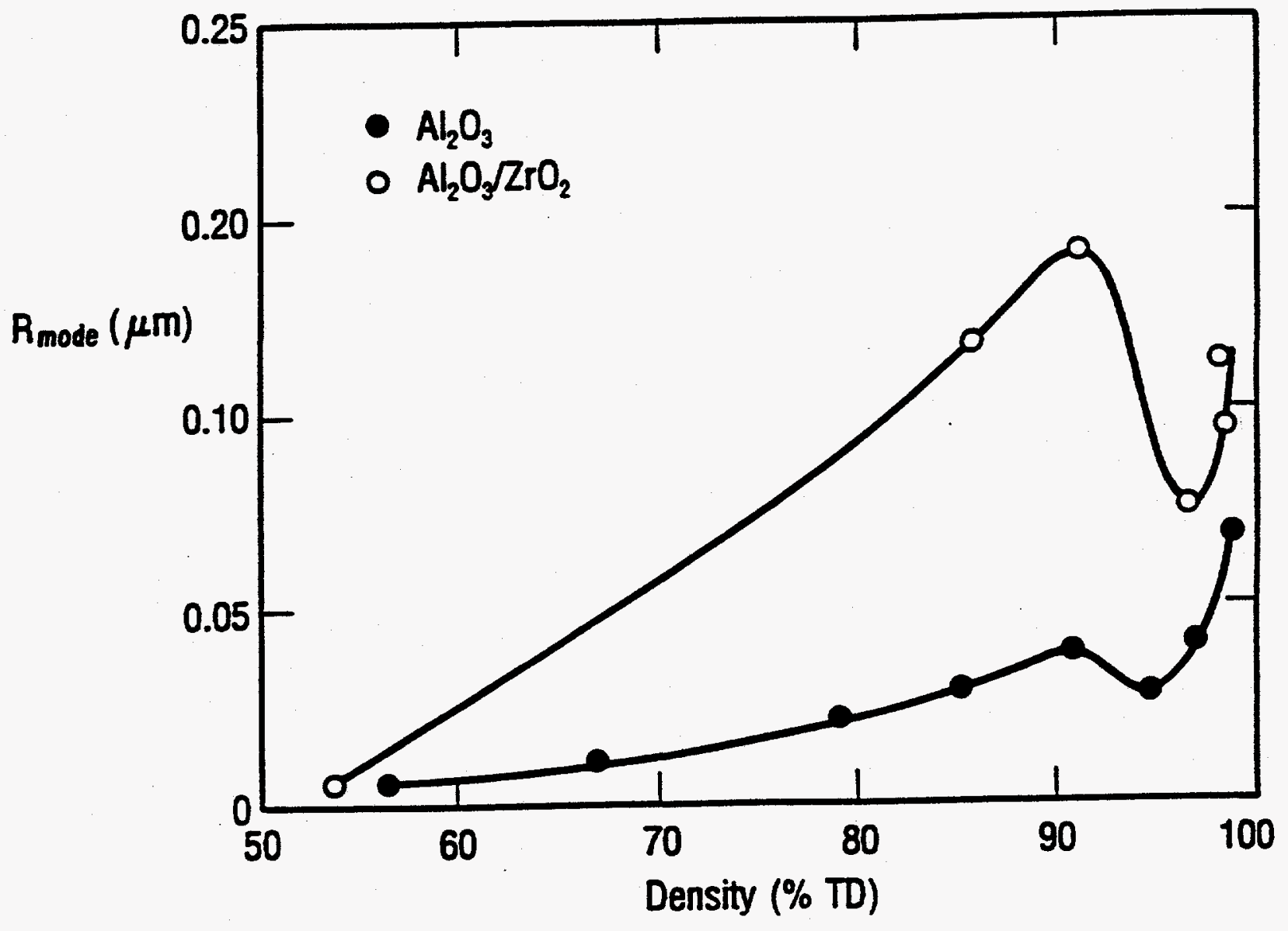

Figure 12. $R_{\text {mode }}$ versus relative density for both series of samples. 


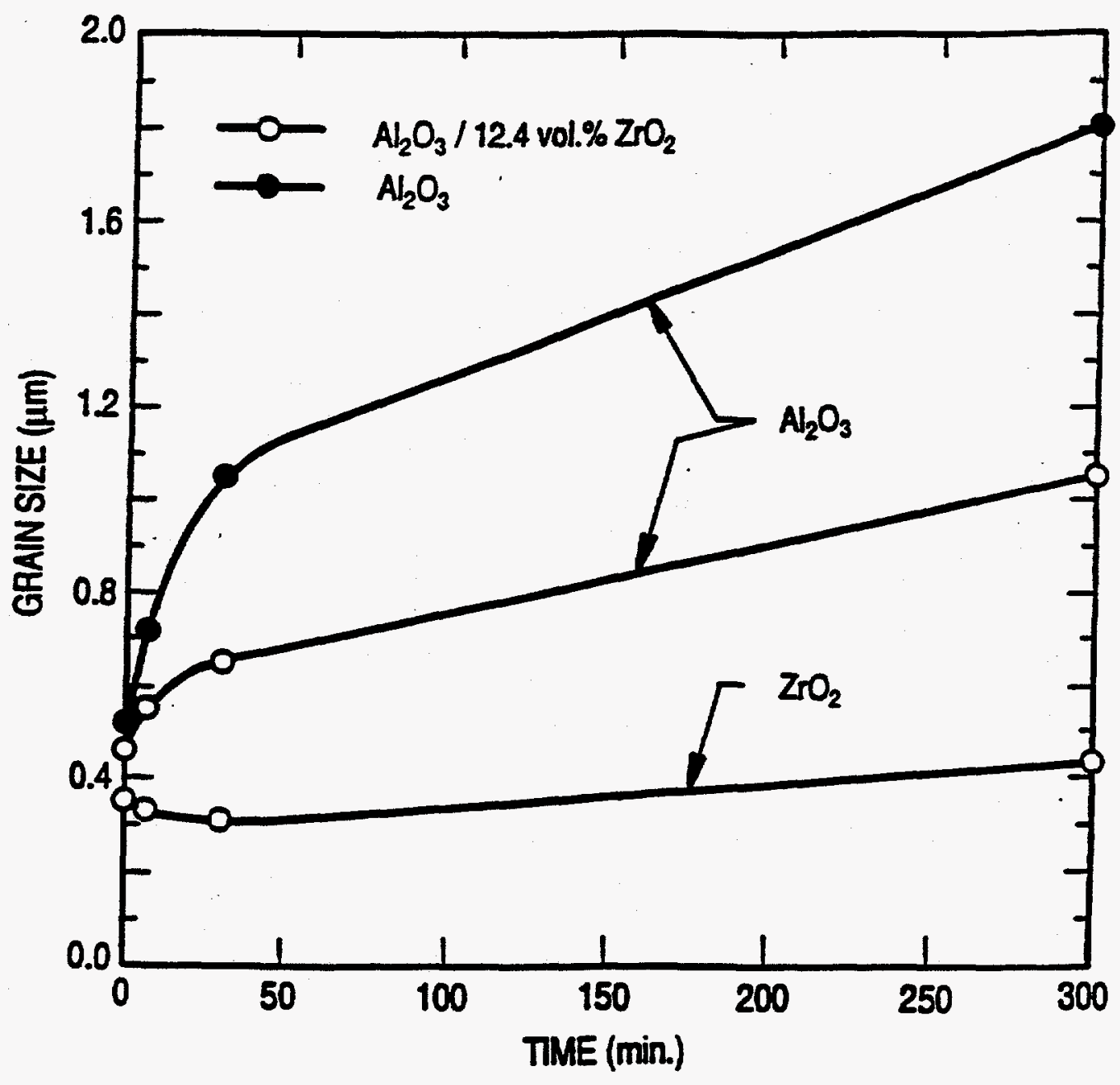

Figure 13. Mean grain size of both $\mathrm{Al}_{2} \mathrm{O}_{3}$ and $\mathrm{ZrO}_{2}$ phases as a function of sintering time at $1600^{\circ} \mathrm{C}$ for both series of samples. 


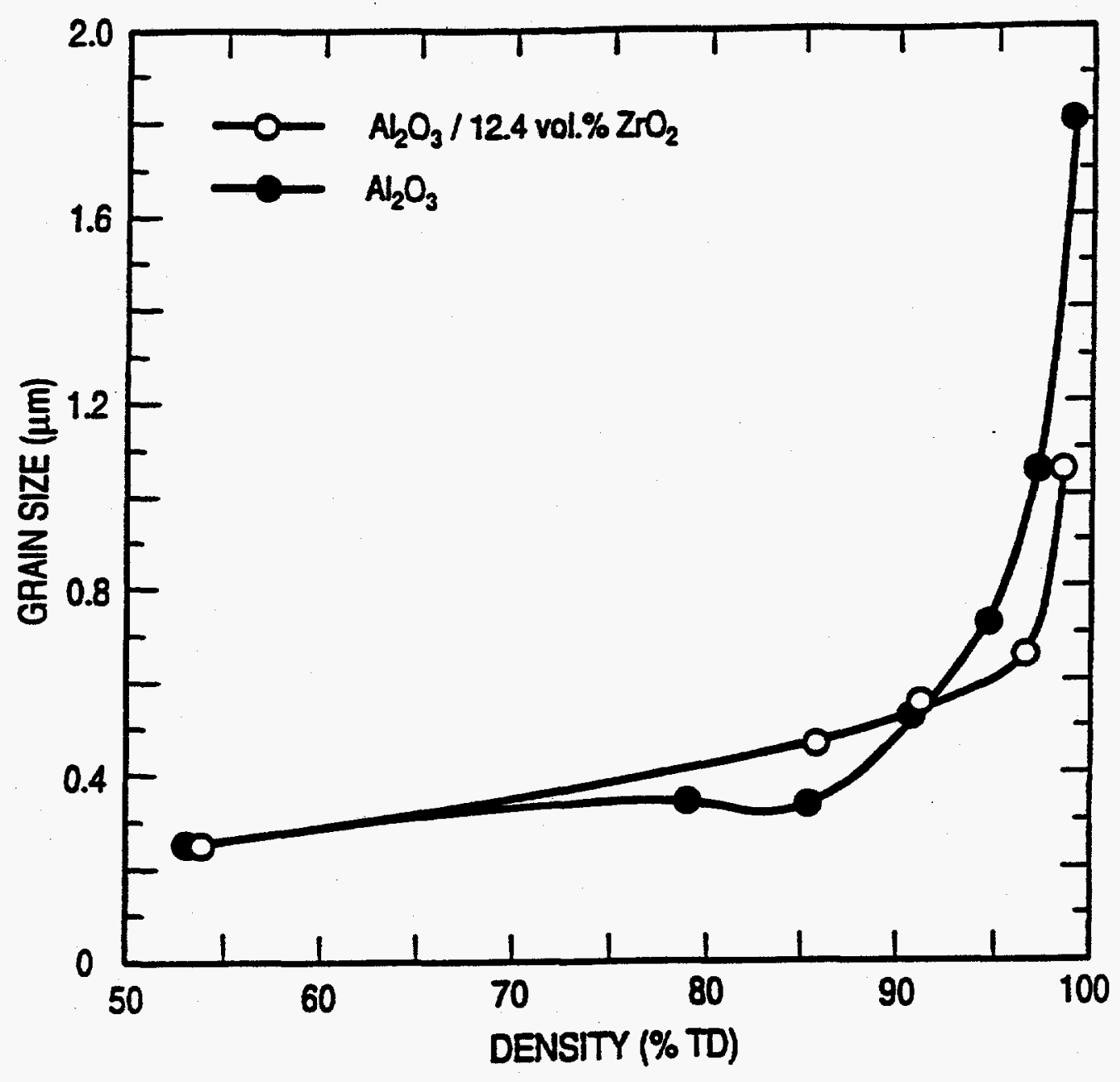

Figure 14. Mean grain size versus relative density for both series of samples. 

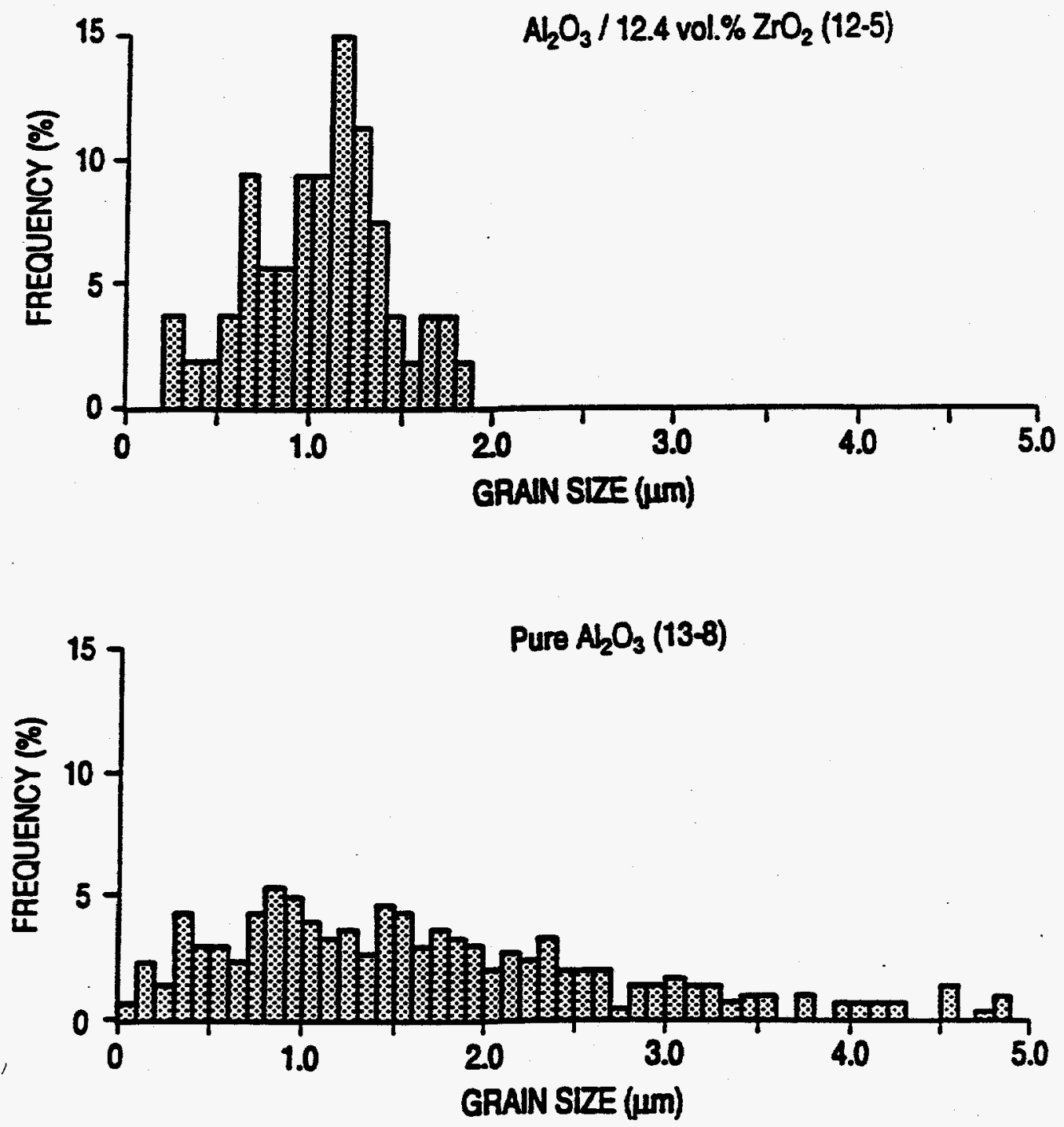

Figure 15. Grain size distribution histograms for 12-5 and 13-8 samples sintered at $1600^{\circ} \mathrm{C}$ for $300 \mathrm{~min}$. 

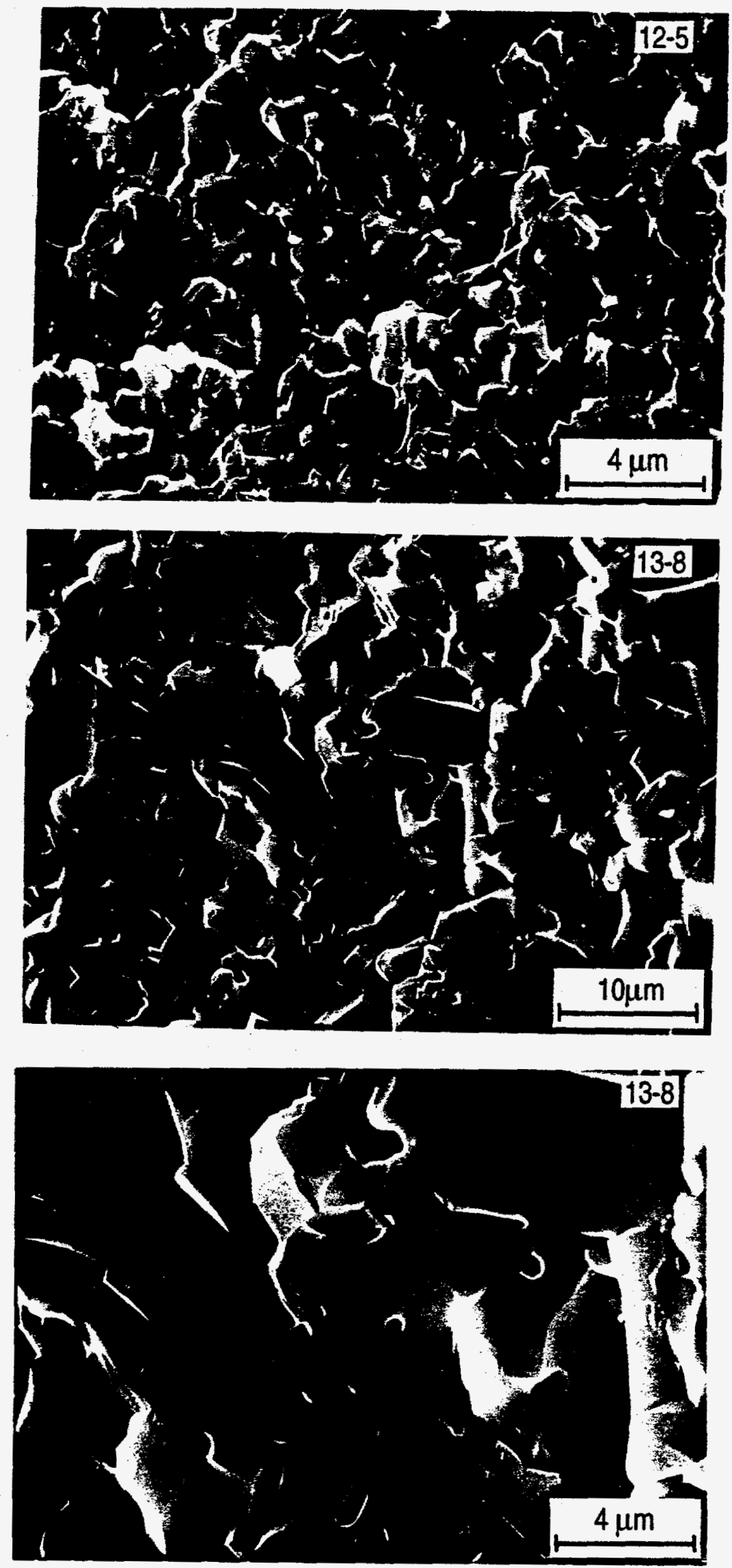

Figure 16. Fracture surfaces of $12-5$ and $13-8$ samples sintered at $1600^{\circ} \mathrm{C}$ for $300 \mathrm{~min}$. 


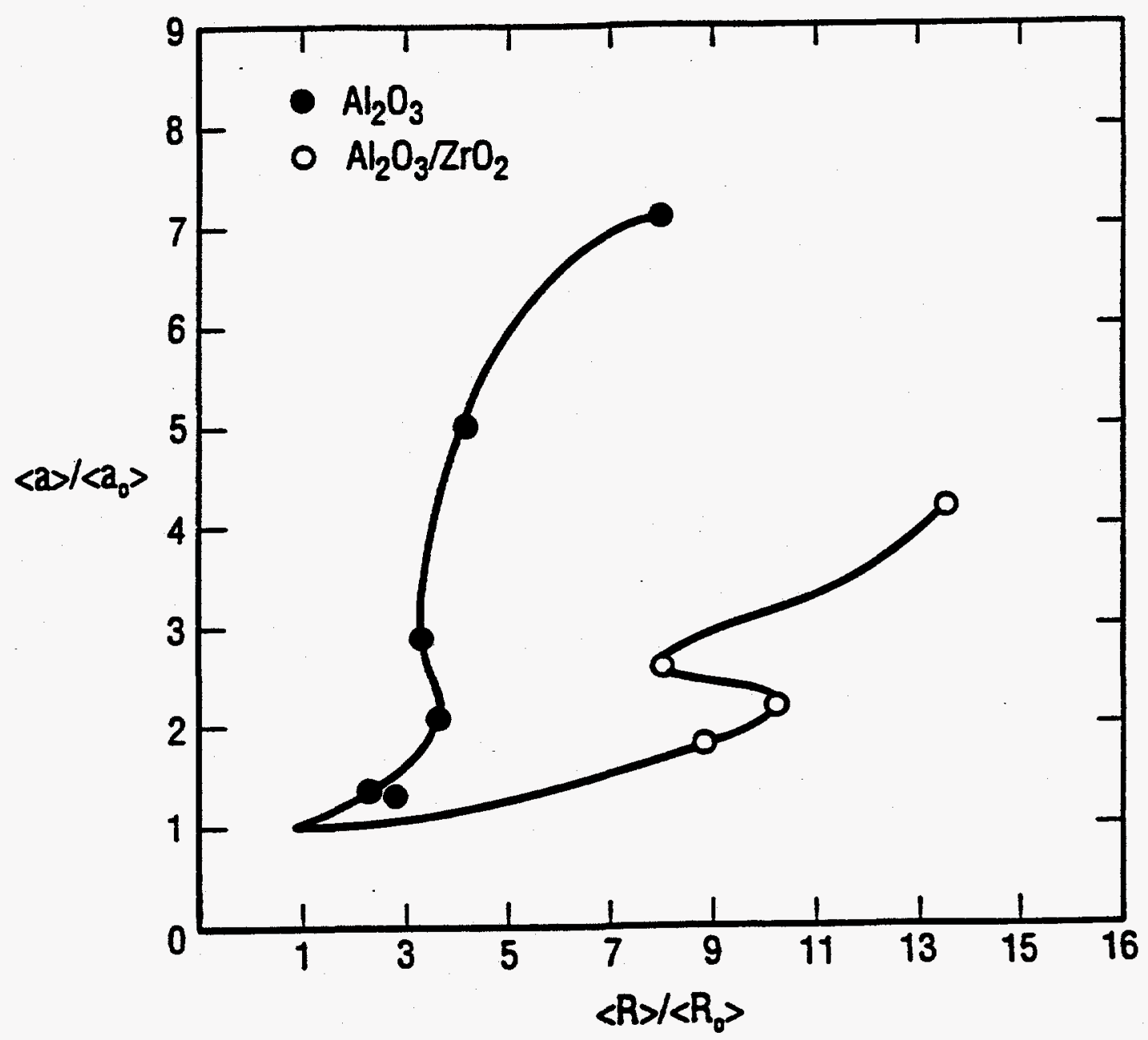

Figure 17. Grain size/mean pore size trajectories for the $\mathrm{Al}_{2} \mathrm{O}_{3} / \mathrm{ZrO}_{2}$ and the single-phase $\mathrm{Al}_{2} \mathrm{O}_{3}$ samples. Both the mean grain size, $<a>$, and the mean pore size, $\langle R>$, are normalized to their initial values in the green compact. 


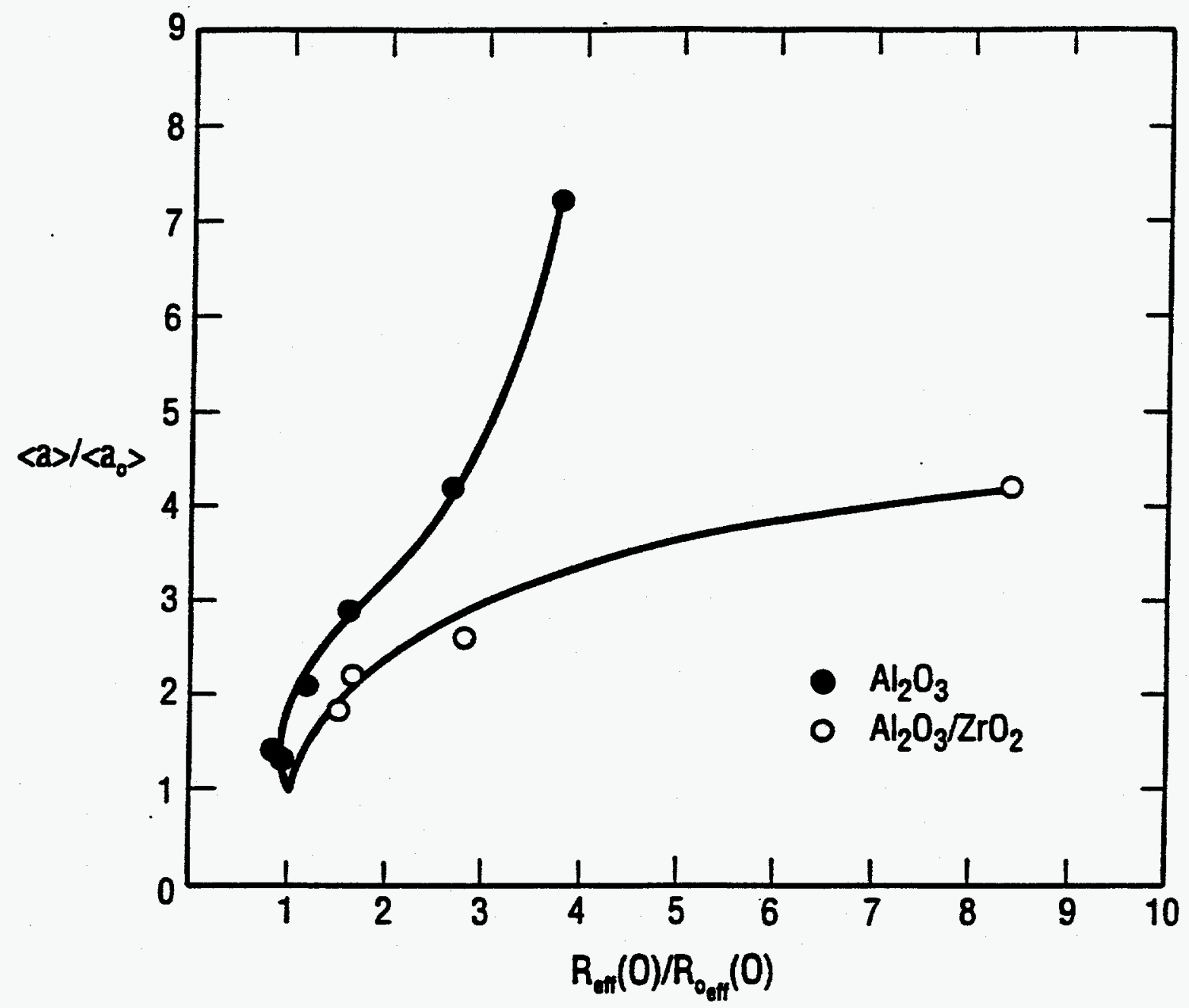

Figure 18. Grain size/effective pore size trajectories for the $\mathrm{Al}_{2} \mathrm{O}_{3} / \mathrm{ZrO}_{2}$ and the single-phase $\mathrm{Al}_{2} \mathrm{O}_{3}$ samples. Both the mean grain size, $<a>$, and the effective pore size, $R_{\text {eff }}(0)$, are normalized to their initial values in the green compact. 


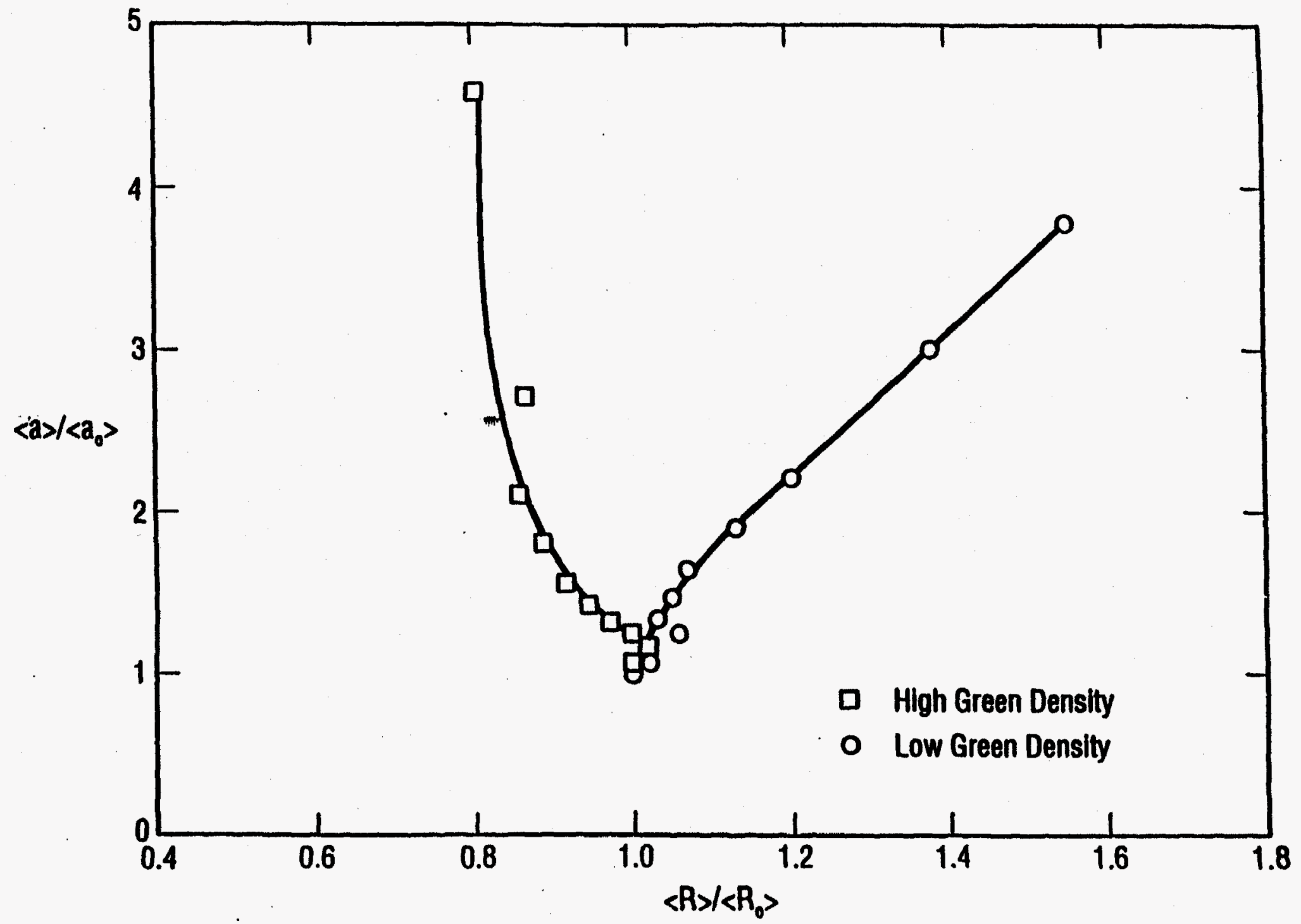

Figure 19. Grain size/mean pore size trajectories predicted for single-phase $\mathrm{Al}_{2} \mathrm{O}_{3}$ compacts by Fang and Palmour ${ }^{22}$ using a statistical sintering model.

Pan and Page, long and Kruger

Page 45 